\title{
المعادن والأحجار الكريمة وشبه الكريمة في بلاد النوبة وأهميتها

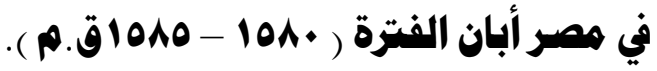

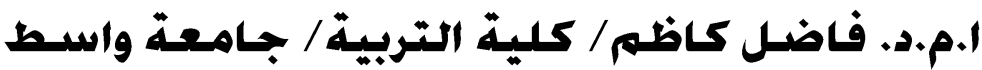

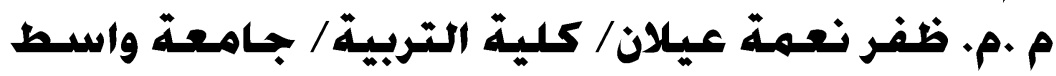

الملنمص:

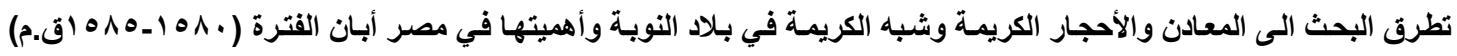

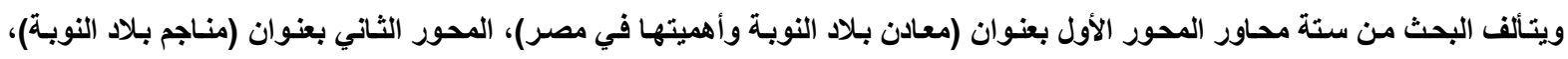

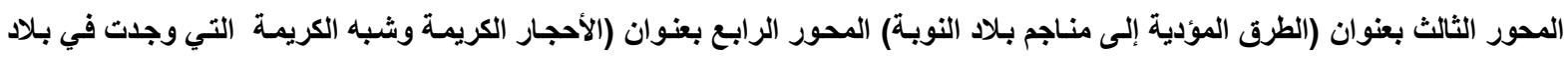

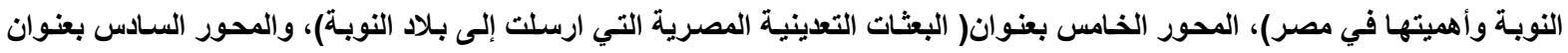
(التعدين المصري في بلاد النوبة) .

Abstract:

The research dealt with minerals, precious stones and semiprecious stones in Nubia and its importance in Egypt within the limits of $101 .-1010$. The research consists of six axes, the first axis (Nubia metals and their importance in Egypt), the second axis (Nubia mines) The third axis is entitled "The roads leading to the mines of Nubia". The fourth axis is entitled "Precious and semi-precious stones found in Nubia and its importance in Egypt". The fifth axis is titled "Egyptian Mining Missions sent to Nubia" Nubia) .

\section{المدفدمة:}

امتازت بلاد النوبة بغناها بثرو اتها الطبيعية والتي تمثلت بالمعادن وكان الذهب النوبي لـه الصدارة من

بين معادنها ويمتاز بوفرته بكثرة مقارنة بالمعادن الأخرى المتواجدة هناك وكان لذهب بـلاد النوبـة أهمية كبيرة

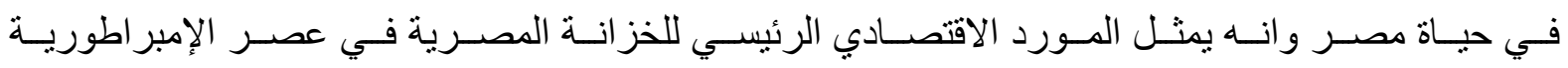

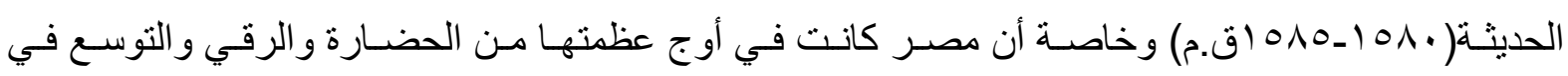
الفتوحات لذلك كان لابد من الحصول على الذهب ذلك المعدن الثمين لكي يلائم بذج بـلاط الدولـة الحديثة ،

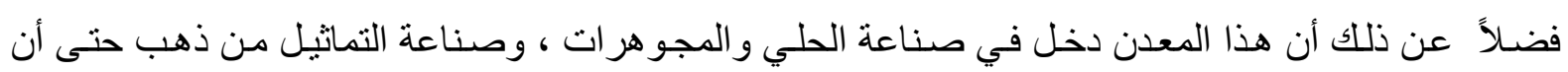
تماثيل الآلهة قد صنعت من هذا المعدن وكان يأتي الذهب على شكل حلقات من بلاد النوبة.

ومـن المعـادن الأخـرى التـي لهـا أهميـة هـي معدن الفضــة والذي لعب دوراً في حيـاة مصـر الدينيـة و الاقتصادية وقد وجدت في بلاد النوبة بشكل قليل هذا المعدن إلا أنه كان أغلى من الذهب لقلة توفره مقارنة مـع الذهب. كذلك من المعادن التي وجدت في بـلاد النوبـة الأخرى هو النحاس الذي كان لـه دور في حياة مصر اليومية والدينية والسلمية والحربية اضافة إلى معادن بلاد النوبة الأخرى التي لها أهمية في مصر مثنل البلاتين،

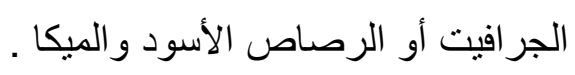

وأيضاً اهتم ملوك الدولة الحديثة بالمناجم التي تواجدت في بلاد النوبة واستثمار المعادن المهمة فيها من الذهب، والفضة، النحاس وذلك لأهميتها في الحياة المصرية وقد ذكرت مسـاعي هؤلاء الملوك المصريين في

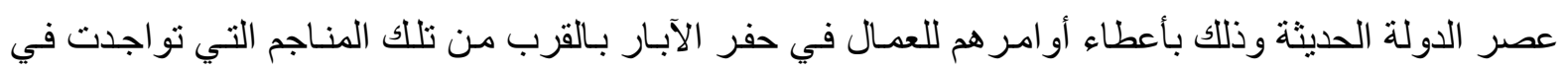


الصحاري وتعبيد الطرق المؤدية اليها وقد وجدت وثيقة قد وردت فيها اسماء مناجم الذهب في بـلاد النوبـة التي عرفها المصريون. كما اهتم ملوك الدولة الحديثة بالطرق الموصلة إلى المناجم في بلاد النوبة . أمسا الأحجـار الكريمـة وشبه الكريمـة في بـلاد النوبـة أيضـاً ظهرت لهذه الأحجـار أهميتهـا في الحيـاة المصرية ودخولها في كثير من الصناعات كصناعة الحلي و المجو هرات المصرية ، اضـافة إلى تطعيم التمـائم التي كانت تلبس كقلادة إذ كانت ترصع هذه التمائم بتلك الأحجار الكريمة والكثير من هذه الأحجار الكريمـة التي وجدت في بلاد النوبة قدوجدت في المقابر الملوك المصريين من عصر الدولة الحديثة في عهد الملك توت هند

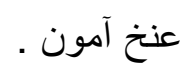

أما البعثات التعدينية المصرية إلى بلاد النوبة إذ أرسلت هذه البعثات بأمر من ملوك الدولة الحديثة إلى

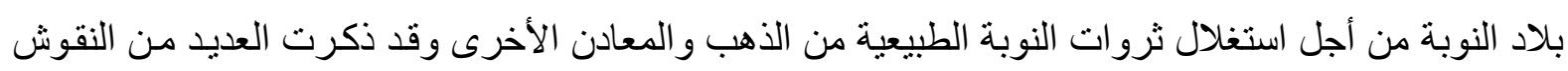

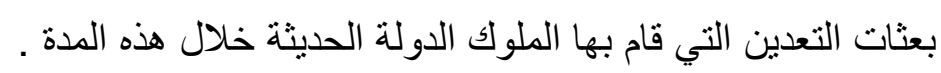

أما التعدين في بـلاد النوبـة فقد خصصت مصر أنشطة سياسية واداريـة خاصـة ببلاد النوبـة إذ وفرت

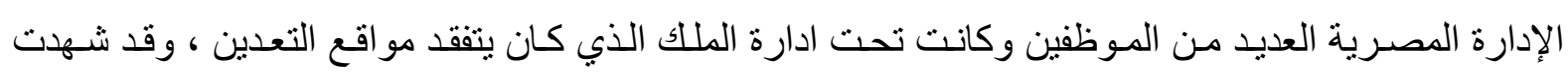
مناطق بلاد النوبة تعدين من خلال المستوطنات المصرية التي شيدت بقرب المعادن التي وجدت في بـلاد النوبـة

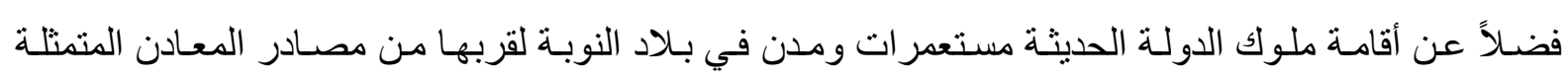
بالذهب المحمل بالكوارتز، وأيضاً وجدت في بو هن آتار صهر نحساس ممـا يدل أن هذه المنطقة كان يتم فيها تعدين النحساس وكذلك "سيسبي" قد شيدها فر اعنـة مصر لتكون مستوطنة لقربها من منـاجم الذهب المحملة فئة

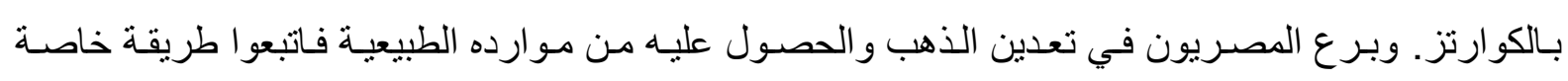

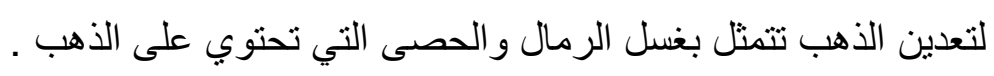

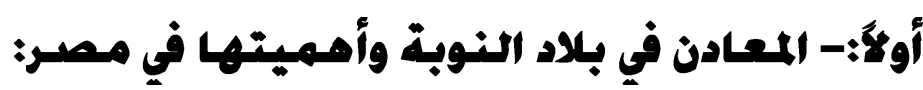

:-1الأهب:

في ذروة مجد الدولة الحديثة ، كانت مصر قد زاد الفرعون ، القابض على مفتاح أفريقيا ، في دخله من المناجم الثرقية، فضلاً عن الجزية السنوية التي تدفعها أهل النوبة الخاضعين لحكمه ، إذ كانت اثثوبيـا أي " النوبة العليا " غنية بالذهب هي أيضاً، حتى تخيل الأغارقة المتمصرون، في أزمنة لاحقة ، أن "جميع الأسرى

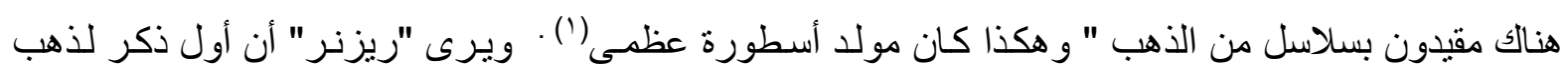
النوبة إنما جاء في الدولة الحديثة(؟) وقد وجدت عدة مر اكز قديمة لاستخر اج الذهب في السودان أي النوبـة العليـا

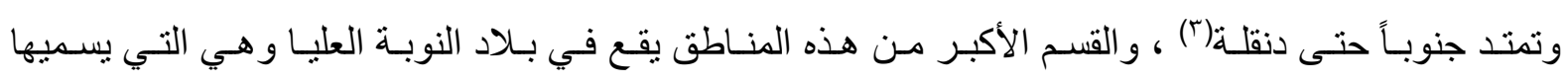
المؤرخون أثيوبيا، ويثير هيرودوت إلى اثيوبيا أي النوبة العليا فيقول " توجد هنا كميات وافرة من الذهب " " ،

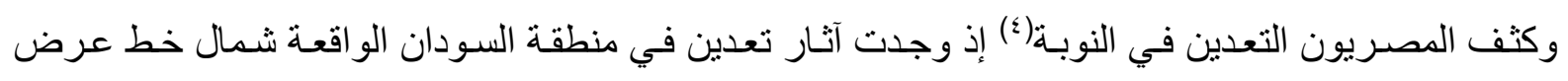
( ا (درجة) حيث يوجد على الأقل خمسة وثمانون مركز اً قديماً هاماً(ه) . 
وقد وجدت في المدينـة المصـرية المتواجدة في النوبـة العليـا ربمـا آثار تعدين للأستخر اج الذهب من عروق الكوارتز والرواسب الحجرية من التلال والصحاري كما هو الحال في مدينـة عمـارة غرب إذ تم العثور

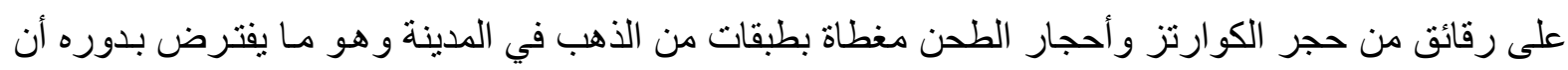
بعض عمليات استخلاص الذهب كانت تحدث في المدينة(؟) .

و إذا مـا ألقينـا نظرة على واردات مصـر مـن كوش أيسام الدولـة الحديثة ، لوجدنا أن كنوزهـا المعدنيـة

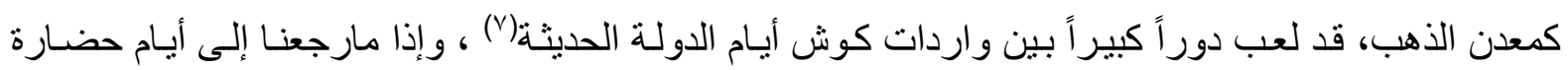

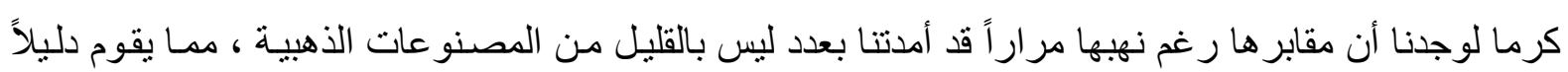
على أن الذهب كان يستخرج بكميات كبيرة من مناجم كوش قبل قيام الدولة الحديثة ولقد ظلت كوش تمثنل مورد الذهب الرئيسي طوال عصر الرعامسـة ، بـليل تلك النقوش المسجلة على معبد الأقصر ، و وعلى معبد مدينة هابو ، وفي بردية هاريس(^) .

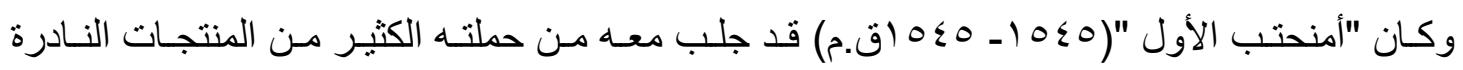

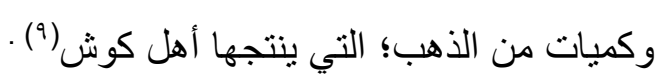
وكان هناك نوعـان من الذهب ، ذهب الجبال ، وذهب الميـاه الذي يُحصل عليه بعد تصفية الغرين

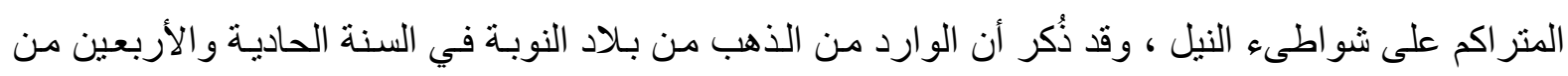

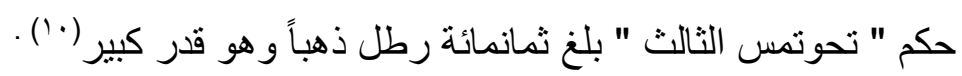

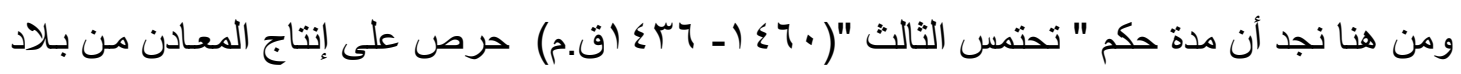
النوبة السفلى و العليا وبصفة خاصة معدن الذهب حيث كانت النوبة السفلى تنتج حو الي ( . . . 1 ) كيلو جرام

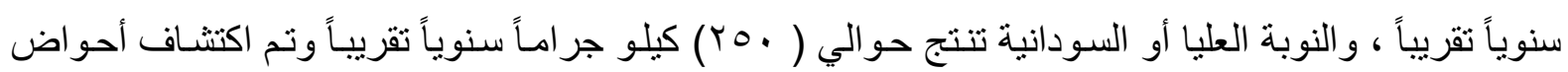

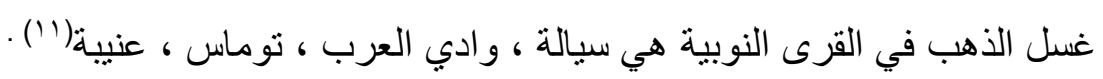
و لابد أن تكون قيمة الثروة التي كانت ترد إلى الخزانة المصرية في عهد" تحتمس الثالث "( • بـ ا -

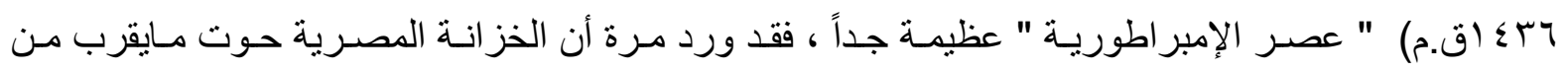

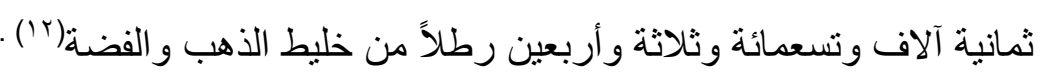

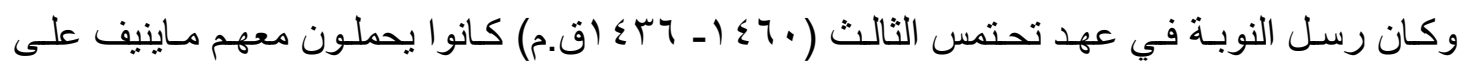

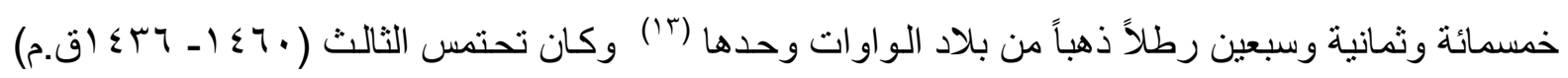
قد وجه همته نحو بلاد النوبة حتى أن رئيس خزانة الذهب و الفضة المدعو" من خبر رع سنب إذ كان يتسلم من

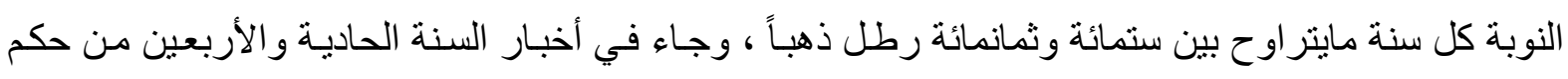

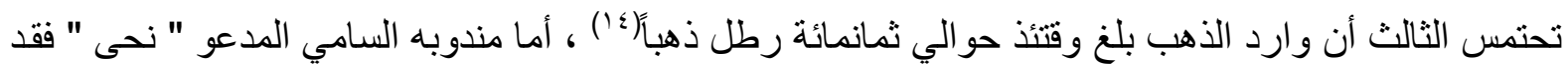
لبث حاكماً لكوش حو الي عشرين سنة وقد زادت في أثنائها واردات تلك الجهات كثير آك(10) . 
noub en " " وذكر في النصوص المصرية " نوب إن كوش " أب الذهب القادم من إقليم النوبـة العليـا

"koush حيث يوضح النص الذهب الذي كان يدفع جزيـة لمصر في عهد تحتمس الثالث من إدارة بـلاد كوش ، وجـاء

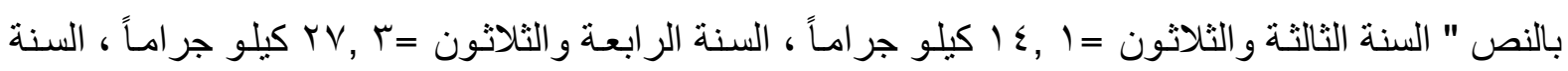

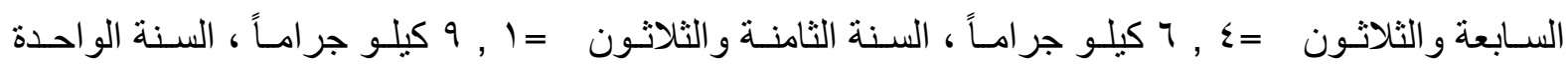

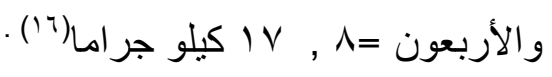

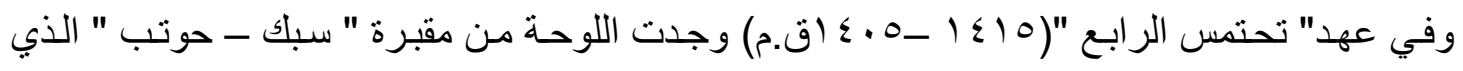

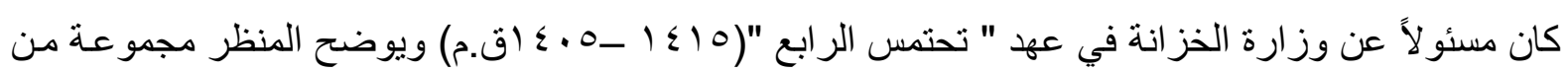
النوبيين يحملون الذهب الذي كان يقدم لفر عون مصر ('v') .

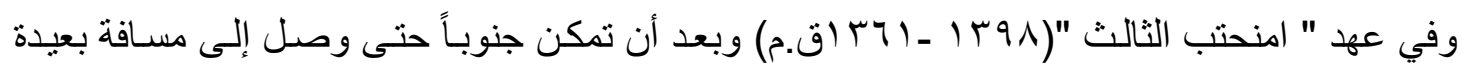
عن منطقة الثلالات ، ويعتبر هذا المكان آخر ماوصل إليه " أمنحتب الثالث " بعد ذلك جمع الملك كميات كبيرة من الذهب لعمار ات طيبة من اقليم " كاروى " بجهة " نباتـا " وبالتـالي يمكن القول بأن حدود مصر الجنوبية

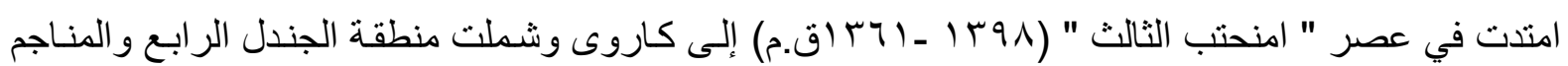

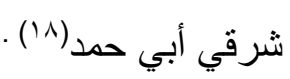

وورد ضمن المناظر التي رسمها " حوى " نائب كوش في عهد الملك " توت عنخ آمون " ، منظر بين

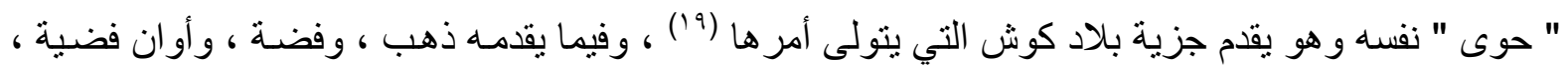

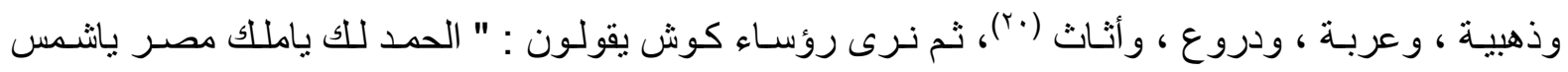
الأقاليم التسعة أعطنا نسيم الحياة الذي تهبه ، حتى نستطيع أن نعيش برضاك الطيب " ودون بمقبرة " حوى " وله نائب كوش في عهد الملك " توت عنخ آمون (rr) " " حضر رؤساء قبائل واوات بالذهب المقرر "(rr) . ولما كان الذهب معدناً إلهياً ، فقد أضفى الحياة الخالدة ، فوهب الذهب " توت عنخ آمون " وكل من شابهه الحياة الخالدة التي للثمس والآلهة ، وامتد هذا الأعتقاد حتى صـار اللون الأصفر بالغ الأهميـة في الرموز الجنائزية ، واطلق على المواضع التي صنعت فيها نماثيل " القرين " " التوابيت " ، إسم " بيوت الذهب " ، وكذلك اطلق نفس هذا الإسم على بعض بيوت التحنيط وحجرات التوابيت بالمقابر الملكيـة ، وكانت الأقنعة التي تغطي وجوه الأطفال المحنطة ، إمـا إن تكسي بالذهب أو تطلاي بـاللون الأصفر ، أمـا أقنعـة الملوك و عظمـاء

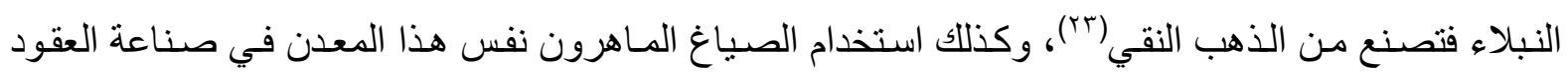
و الأساور و الخواتم و الحلى الصدرية ، و غيرها من التمائم القوية الأثر ، التي تزين جثة الملك المحنطة وجثت

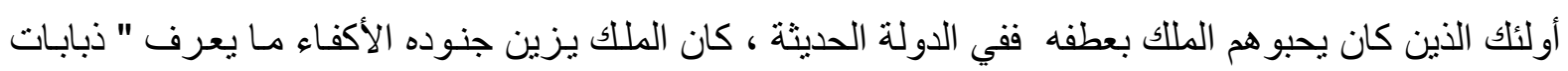

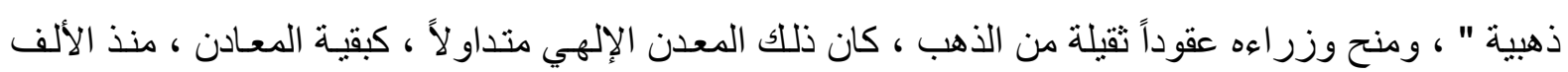


الثاني قبل الميلاد على الأقل(\&)(أصبح الذهب في عهد " توت عنخ آمون " يتدفق بكميات، وفيرة وهائلة ؛

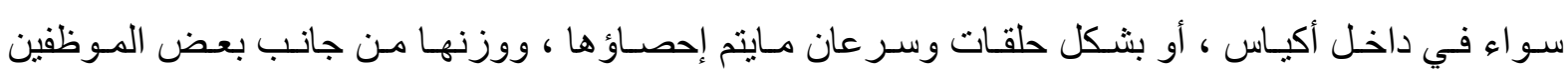
المصريين الذين قاموا أيضـاً بتخزينها(ب0). أمـا في عهد سيتي الأول من الاسرة التاسعة عشر كان الحصول

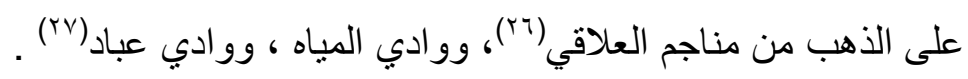

ولقد أمدتنا أقدم مقابر " الكرو " التي تخص أسـلاف ملوك نبتة بكمية كبيرة نسبياً من الذهب ، على الرغم من صغر حجمها وكثرة نهبها قديماً في العصور المختلفة ، فأقدم قبر منها أمدنا بمـا قيمته حوالي (YN) جنيهاً استرلينيا(^^إذ كان الذهب النبتي أرقى ذهب في العالم القديم وقد وجد في متحف الفنون الجميلة في بوسطن إذ يضم مجمو عة من المجهورات الملكية النبتية من أقر اط ، و القلائد ، والدروع ، و الأسـاور ، و والخواتم

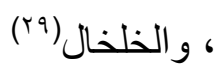

إذ كانت النوبة تعد مصدراً غنياً للمواد الخـام لصـائغ المجوهرات القديم، كما عثر في مقبرتين أيضـاً

على تمثال صغير من الذهب الخالص ، و على بعض قطع الزينة الذهبية ، و إن ذلك وحده ليشير إلى مقدار مـا كانت تضم تلك المقابر من صناعات ذهبية مما كان يكثر استعماله بين هؤلاء القوم ، هذا من ناحية وفرة الذهب لهب في كوش باعتباره من أهم عناصر القوة عموماً ، لذلك عد الذهب كأحد العناصر المكونـة لثروة كوش المحلية

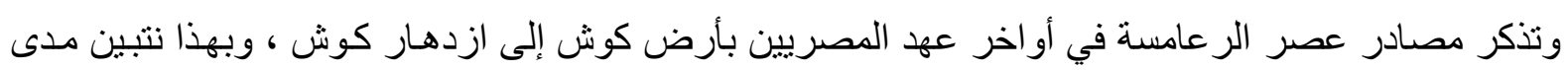
ما كانت تتمتع به كوش من مصادر للثروة ساعدتها لكي تتبو أ مكانها(·r) .

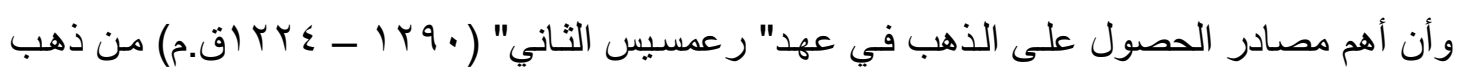
نسوت تاوي " عروش الأرضبين " وهو جبل " البرقل "، ومن منطقة أبو حمد في منطقة الجندل الرابع ، وذهب " جبل عمو " في المنطقة الواقعة على ضفتي النهر بين صولب وكرما شمال وجنوب سابو عند الجندل الثالث ومن منطقة تاسيتي بين شمال سمنة وجنوب الثـلال الثاني، وأكيتا من منـاطق و ادي العلاقي ، وووادي

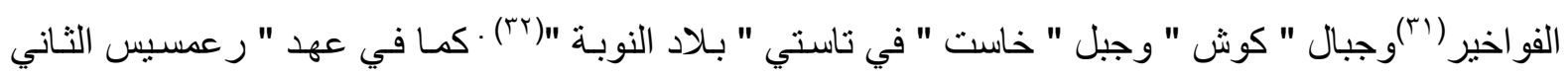

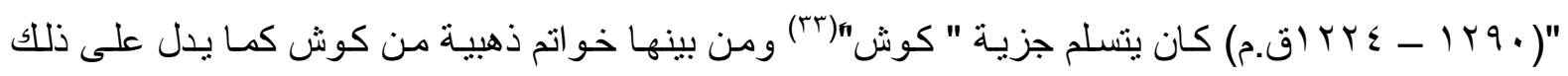
المنظر الذي وجد له في معبد " بيت الو الي " "الملك جالسا في خيمـة على عرشه يتقبل هبات كوش يقدمها لـه

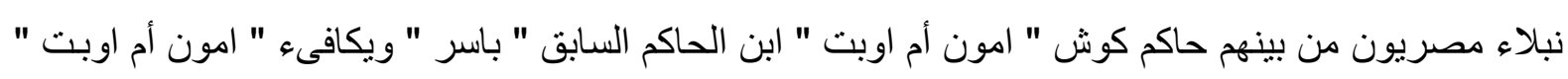
بسلاسل ذهبية جز اء لخدماته وان الجزية المتنو عة مكونـة من خواتم ذهبية وأثناث من الأبنوس و العـاج وجلود

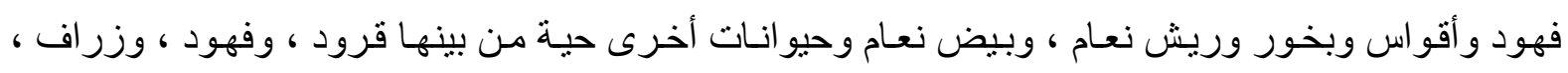

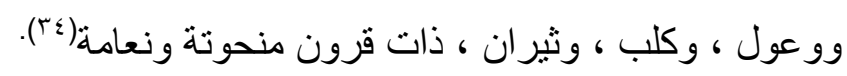

ويتضح من النقوش المحفورة في غرفـة الكنز بمعبد مدينـة " حابو " أو " هـابو " بالأقصر " من عهد

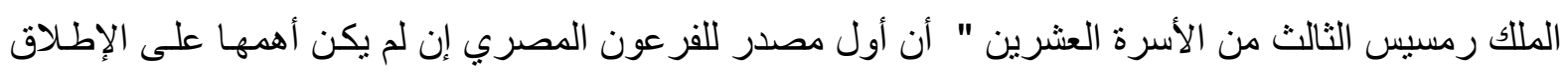
من مصسادر استجلاب الذهب ، كان من " نوب إن كوش " noub en koush " " أي " الذهب القادم من 
كوش " و هي الجزء الجنوبي من بلاد النوبة ضمن مصادر الذهب التي استغلت في عهد هذا الملك(ro) أيضـاً من وادي العلا في في نوبيا ، و أرض العبيد(بr) .

:- بالفضة

ولعبت الفضـة دور مهم في كافة مجـالات الحيـاة الدينيـة والاقتصـادية والفنيـة ، غير أن الدور الديني و الرمزي الذي لعبته الفضـة بجانب الذهب ، يعتبر أهم الأدوار ويعد البعد الديني والرمزي لها هو المحرك

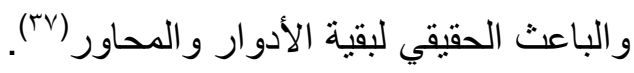

و لاشك أن الفضة كمعدن نفيس ظلت تشير بشكل أو بآخر الى مفهوم الخلود و عدم الفناء(^^) وفي الديانة

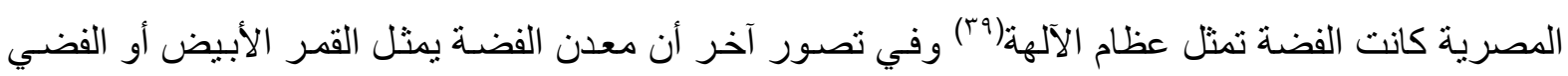

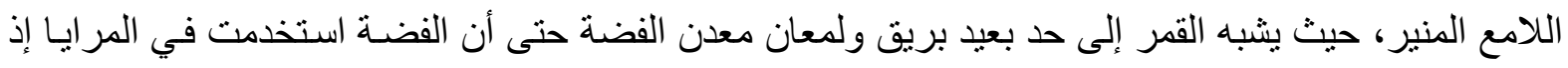

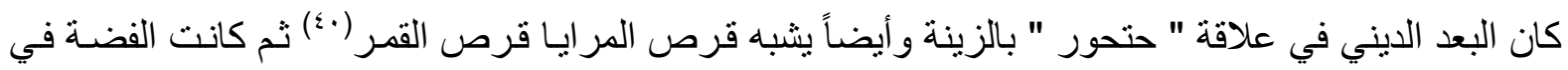

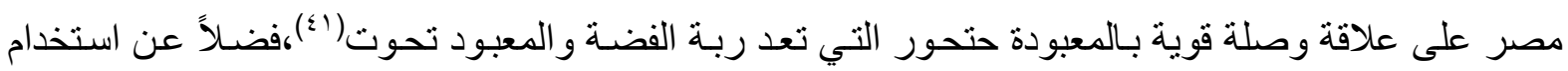

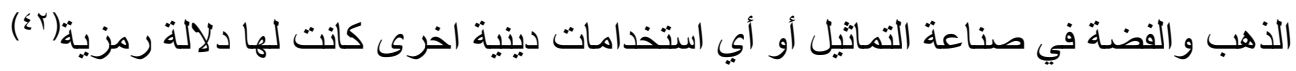
وقد ورد ذكر معدن الفضة في بـلاد النوبـة من ضمن نصوص الجزيـة في عهد الدولة الحديثة(بـأوقد وجدت على كثير من مقـابر كبار الكهنـة وأصـحاب الوظـائف العليـا في الدولـة في عهد " تحتمس الثالث "

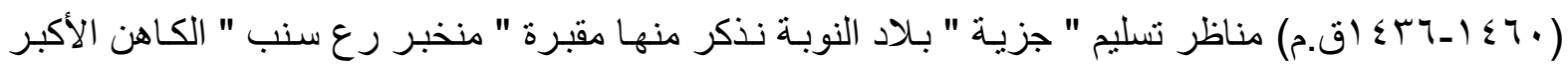
للاله آمـون الذي كان رئيس خز انـة الذهب و الفضـة إذ كان يتسـلم من النوبـة كل سنـة مـايتر اوح بين سنمائة

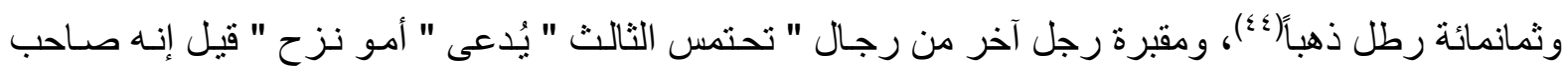

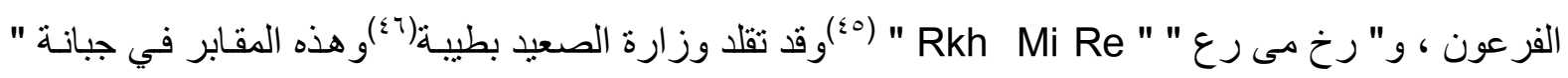
شيخ عبد القرنة " بطيبة الغربيـة ، وممـا صُور على هذه المقابر صور رؤسـاء هذه البلاد يُقبلون الأرض بين

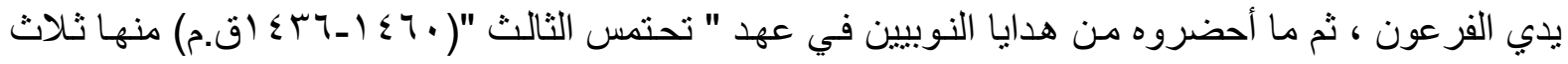
سلات مملو هة من السام " خليط من الذهب و الفضـة " و أيضـاً نشـاهد ثنلاث حلقات من الفضــة وضعت في سـلة

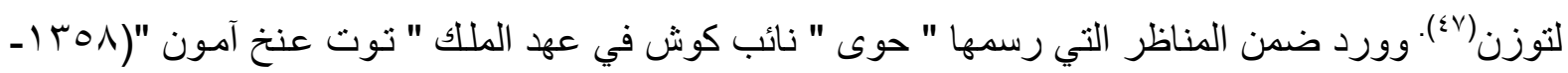

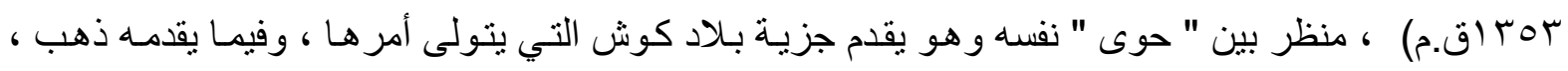
وفضة ، وأوان فضية ، ثم نرى رؤساء كوش يقولون : " الحمد للك ياملك مصر ياشمس الأقاليم التسعة أعطنا

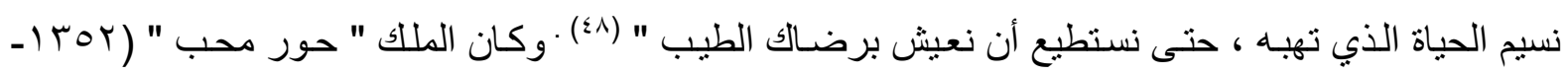
• اس ا ق.م) يأخذ الجزية من السود معدن الفضـة كما تشـهد بذللك نقوش مقبرة الكرنك هذا ماكان من العائلة

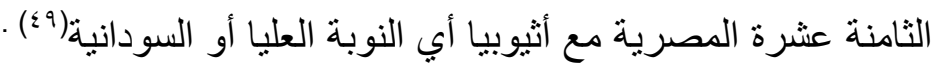

وورد ذكر الفضة في مرسوم الملك سيتي الأول الذي وصف فيه ثروات معبد منطقة " نوري" بالنوبـة

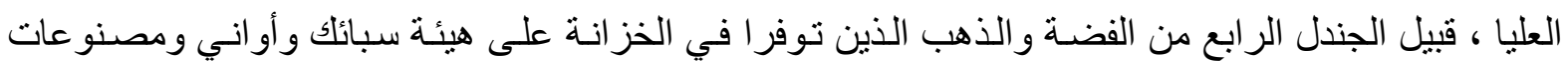

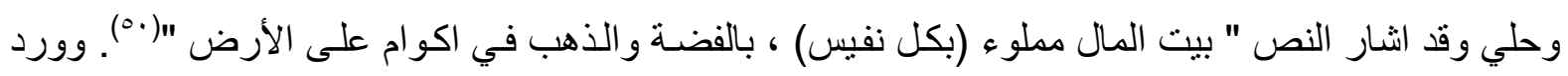


لفظ الفضة في نقوش أحد الهريمـات الخاصـة بالمشرف على الخزانـة لثـؤون النوبـة ، المدعو " حور نخت "

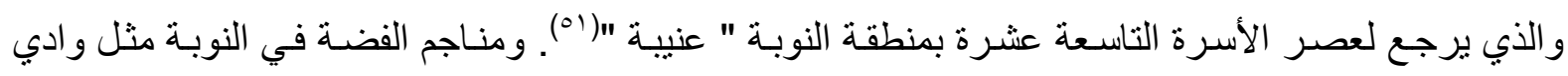

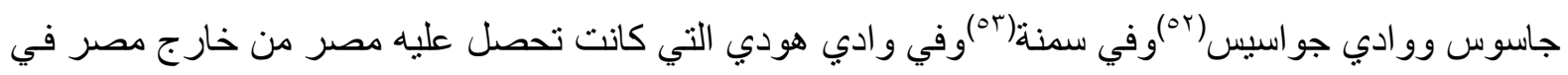

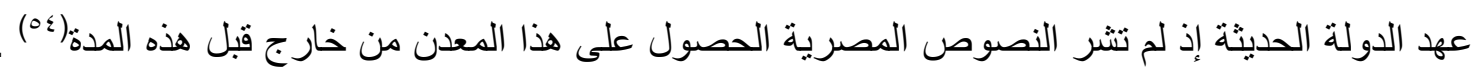

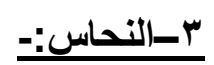

وقد استمر احتياج مصر من النحاس ينز ايد خلال عصر الدولة الحديثة بسبب الدور القيادي التي كانت

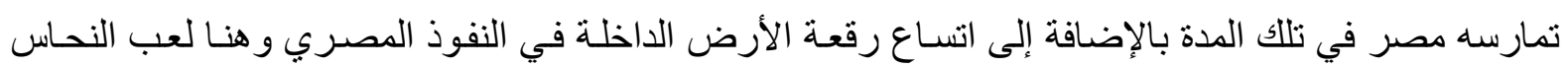
دوراً رئيسياً في شتى الأغر اض اليومية و الدينية والسلمية والحربية(00) . وكان لابـد من ايجـاد طرق للحصول

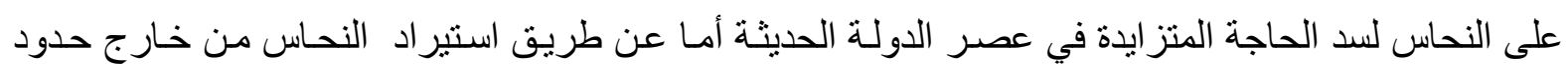
البلاد ، أو عن طريق اقامـة المعاهدات التجاريـة مـع البلاد التي تتوفر فيها هذا المعدن أو يرجع إلى النفوذ فئه المصري على بعض المناطق مثل الاستيلاء على مناجم النوبـة وكان ذلك في سبيل ضمان استمرار الحصول

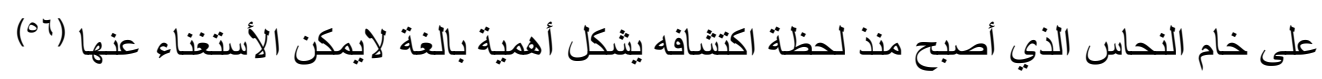
وخلال عصر الدولة الحديثة بدأ الفنانون يصنعون أثكالاً صغيرة من النحاس تمثل الآلهة ، حيث زادت

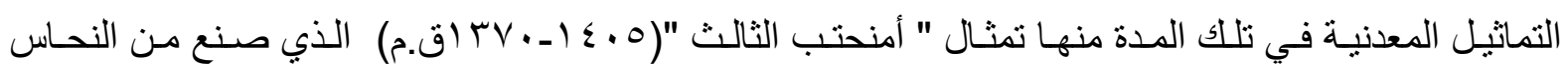

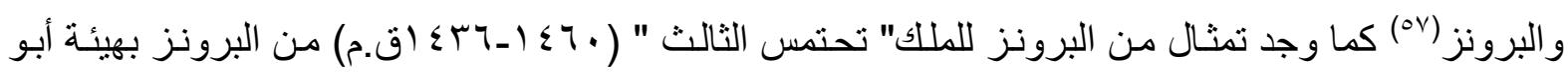

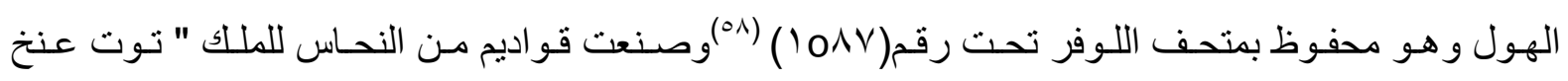
آمون"(09) وكذلك النصل كان من النحاس في عصر الدولة الحديثة(·") هناك تمثنال من البرونز للملك " رمسيس التاسع " يمثل الملك و هو يحمل انـاء في وضـع تقديم(آ) وكان توظيف النحساس في ترصيع العيون قد تفنن المصريين القدماء في مختلف العصور في صناعة العيون الصناعية لتركيبها مكان العيون الطبيعيـة للتماثيل

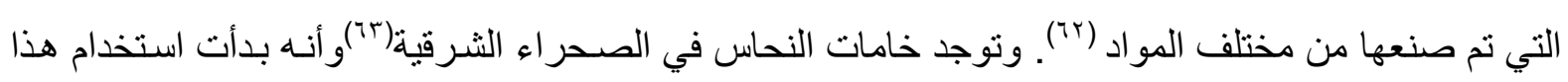

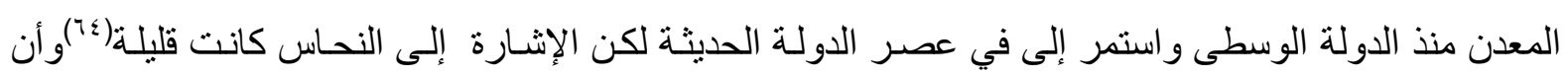
هذا المعدن كان يحتوي على على نسب من الذهب والفضة كما وجد الإزميل الذي عثر عليه في بـلاد النوبـة ؛ وأن وجود نسبة من الذهب والنحاس في خـام النحاس فهي ظـاهرة ليست مجهولة في الصحر اء الثرقية التي

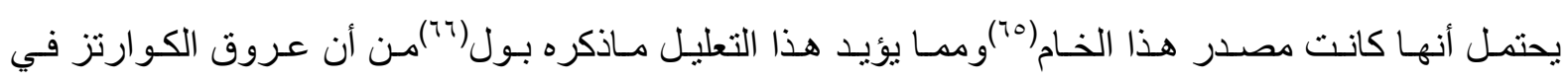
الصحر اء الثرقية تحتوي على النحاس بالإضافة إلى الذهب ولعل استر ابو كان يشير إلى صحر اء الثـرقية حين

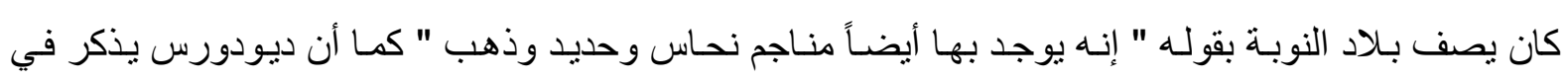

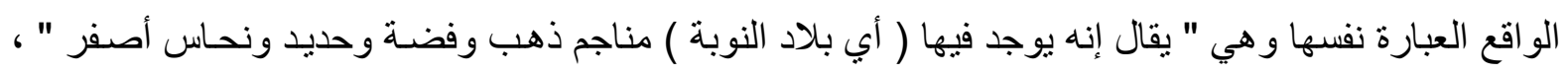

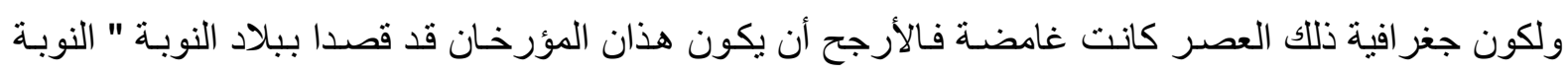
الجنوبية "(TV) التي كانت في السودان أو السودان عموماً حيث توجد مثل هذه المناجم ، ولم يقصد بها بـلاد النوبـة

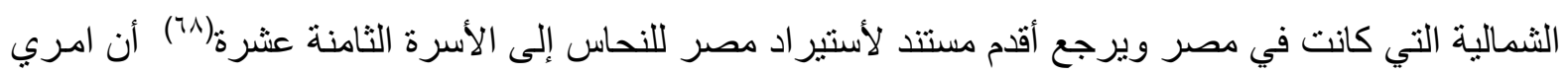

\section{$-Y \leqslant \Lambda$.}


عثر في منطقة بو هن على مساكن و أفران صهر وخبث وقو الب النحاس(79)، إذ كان النحاس برسل إلى مصر في عصر ها وفي عصر الأسرة التاسعة عشرة (•)و أن أهم مناجم النحاس قدوجد نقش نص من من عصر الأسرة

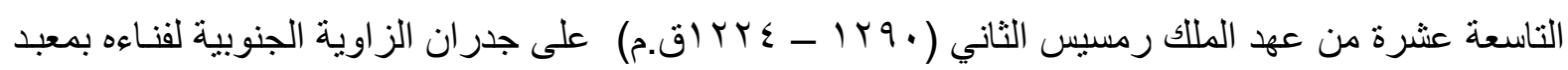

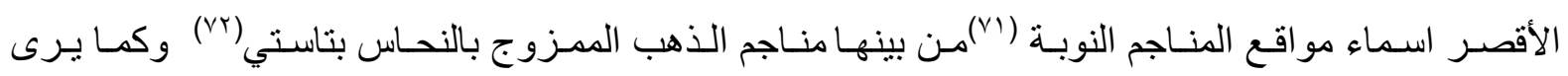
جاردينر (rr) أن هذه المنطقة هي أرض النوبة، ومناجم كوبان التي عثر فيها على أكو ام خبث لصـهر النحاس(Yع) ومناجم اكيتا التي احضر منها رمسيس الثاني من هذا المنجم معدن النحاس (V0) ومنـاجم أبو سيالة ، و ومناجم

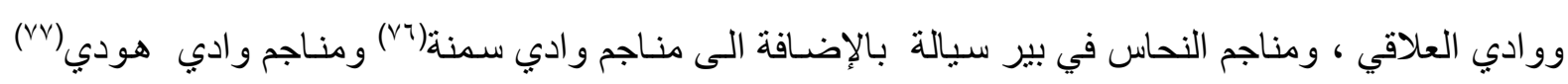

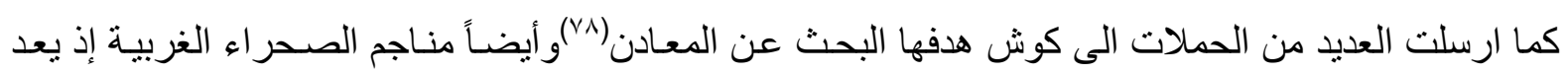
طريق درب الأربعين أهم الطرق التي تصل الى منـاجم التي هي في جنوب الثـلال الثالث (Y9) ومنـاجم النحساس

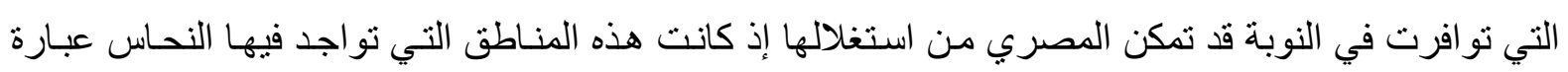
عن كتلة صخرية مرتفعة مباثـرة وقد لعبت جيولوجيتها دوراً هامـاً في جذب السكان الأوائل اليها نظر اً لمسا تحتويه من تكوينات منتشرة في صخور ها التي تمثلت فيها عروق النحاس و الذهب ورو اسب الرخام والألبستر (•A ).

؛

لايوجد البلاتين في الطبيعة إلا خالصاً ، غير أنه لايكون نقياً أبداً بل يكون دائماً مختلطاً ببعض الفلزات

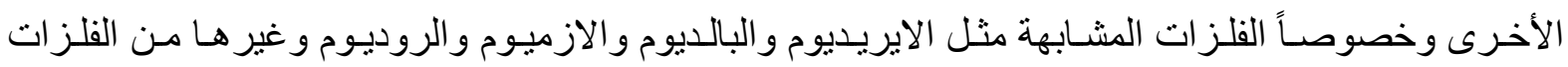
الأخرى كما انه كثير ا مايكون مختلطاً بالذهب أيضاً وتم العثور عن وجود البلاتين في بعض الحلى الذهبيـة التي وني يرجع تاريخها إلى الأسرة الثامنة عشرة وأنه وجد البلاتين في مناطق البحر الأحمر وأيضـاً في وجد مـع الذهب

الذي وجد في النوبة العليا( المان.

\section{هـالجرافيت أو الرصاص الأسود :-}

هي مادة طريـة ذات لون أسود أو رمـادي يتركب من الكربون وبعض الثوائب و وهو في مصر في أحجار الثست المحتوية على الزمرد المصري والميكا وقد عرف هذا من عصر الأسرة الثامنـة عشرة ووجدت منه في عنيبة ببلاد النوبة وقطع صغيرة من كرما بالنوبة العليا (rه). 7-الميكا:

و هي أحد المركبات الأساسية في كثير من الصخور كالجرانيت و الثست ووجد هذا الخام في أبو جريدة

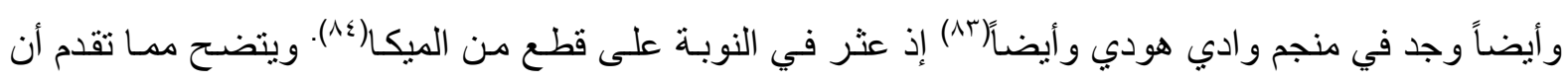
لهذه المعادن التي وجدت في النوبة كان لها دور كبير في الصناعات المصرية وفي ازدهار مصر الحضاري

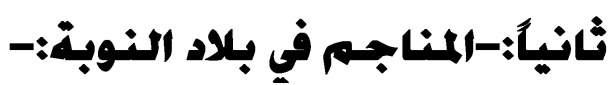
-

ازدادت في عصر الدولة الحديثة كميات الذهب المستخرجة من المنـاجم ويمكن القول أن سياسـة مصر

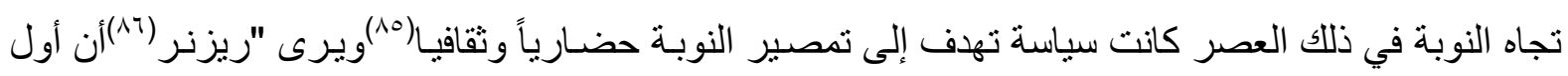
ذكر لذهب النوبة إنما جاء في الدولة الحديثة 
ونجد أن" أمنحتب الأول " انتقل من منطقة " بو هن " نحو منـاطق منـاجم الذهب ، الواقعة غرب كوش

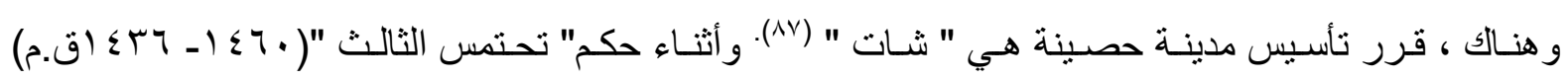
وصلت إدارة النوبة التي كانت في يد الحاكم " نحى " إلى أعلى المستويات ومن الو اضـح أن العمل في منـاجم

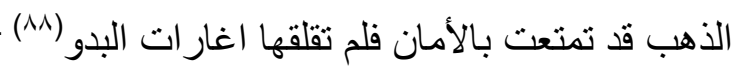

وكانت مناجم واوات في " الجزء الثمالي من اقليم النوبـة إقليم النوبـة السفلى " إذ ورد ذكر هذا الاسم

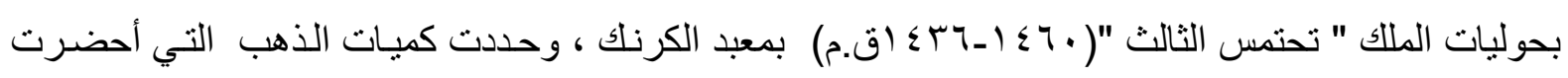
من النوبة لأول مرة في عصر الدولة الحديثة ، حيث جاء على الجدران التي تحبط بحجرة قدس الأقداس بمعبد الإله " آمون " بالكرنك ، نص عن الحملة التاسعة لتحتمس الثالث لبلاد آسيا ، و هي في السنة الرابعة و الثثلاثين

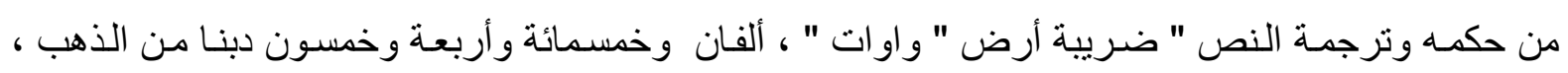

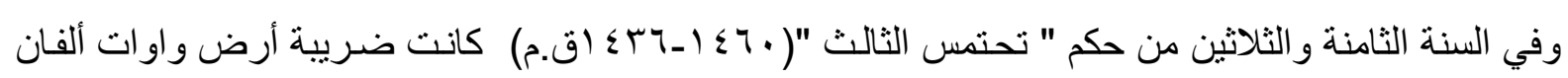
وثمانمائة وثثلاثة وأربعون دبنا من الذهب(19)، ويوجد نص بخصوص الحملة السادسة عشرة ، في السنة الثانية و الأربعين من حكم هذا الملك وترجمة النص " ضريبة واوات هذا العام : ألفان وثثلاثمائة وأريعة وسبعون دبنـا

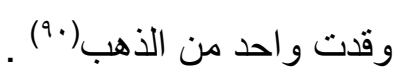

وقد ذكر في عهد " تحتمس الثالث " منـاجم صحر اء تاسيتي " و هذه المناجم تغطي المسـاحة المتدة مابين شمال سمنة وجنوب الثلال الثاني ، وبالتالي فهي تشمل منطقة واوات ، وقد تكون تاسيتي بديلاً لو اوات الذي قل استخدامه في عصر الدولة الحديثة ، ولذلك منطقة تاسيتي تشـمل المناطق الجنوبيـة من و ادي العلاقي وكان قد سجل بمقبرة " رخميرع " الوزير في عهد " تحتمس الثالث " ( ـ جـ ا ـ جس؟ (ق.م) حضور وفد من "

تاسيتي " لتقديم الضريبة وذكر نوب إن كوش " إي الذهب القادم من إقليم النوبة العليا(9) .

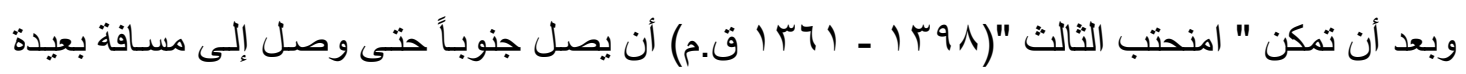
عن منطقة الثلالات ، ويعتبر هذا المكان آخر ماوصل إليه " أمنحتب الثالث "( جمع الملك كميات كبيرة من الذهب لعمار ات طيبة من اقليم " كاروى " بجهة " نباتـا "(זه) وبالتالي يمكن القول

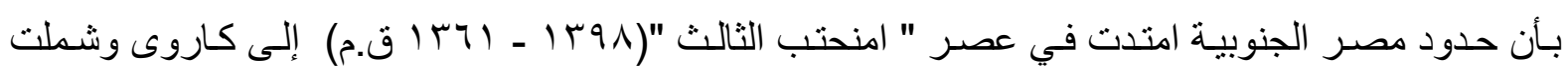

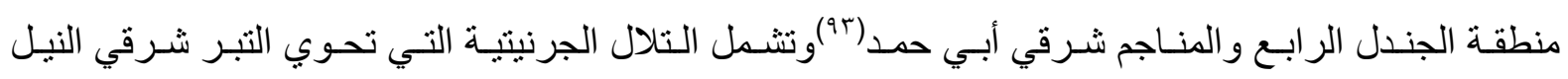

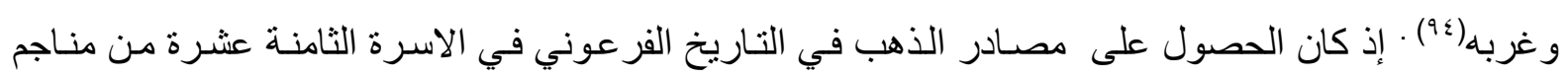
كاروى ، وكوش ، وبونت والاقاليم الجنوبيـة الاخرى(90) . ولكي يستمر سيتي ورمسيس الثاني من الأسـرة

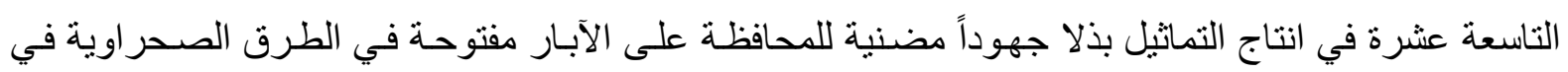
كوبان و غير ها حيث مو اضـع الكوارنز المحمل بالذهب فعدم وجود المـاء ، يعني عدم وجود عمال المنـاجم ،

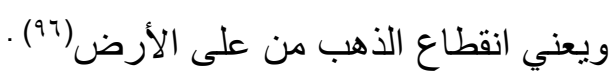

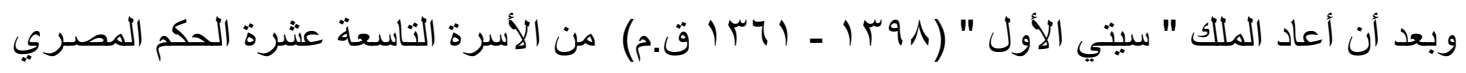

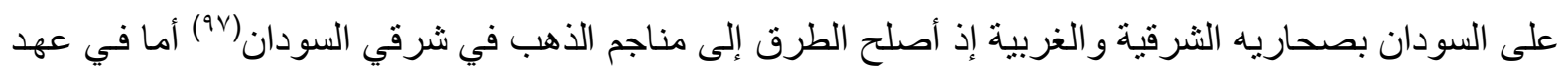




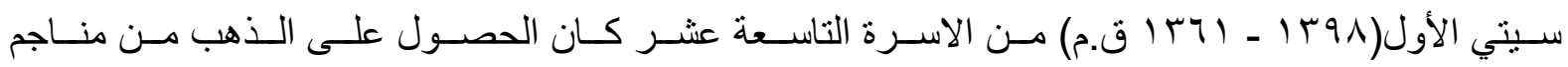
العلاقي (^^و أيضاً كان الملك " سيتي الأول " قد استثمر مناجم الذهب في بلاد النوبة(99)(إذ وجه عنايته إلى العمل في مناجم الذهب النوبية وكان الانتاج في و ادي العلاقي قليلا بسبب عدم وجود المـاء وليزيد هذا الاتتاج حفر

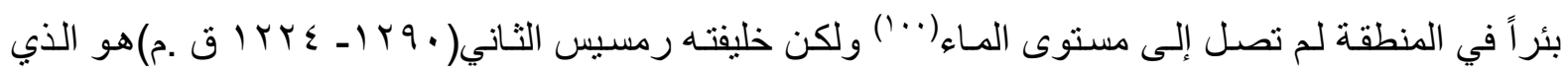
جنى ثمار تلك الجهود(1 +(إذ اهتم باستخر اج الذهب ، وتعبيد الطرق ومسالمة السودانيين(r. (1) .

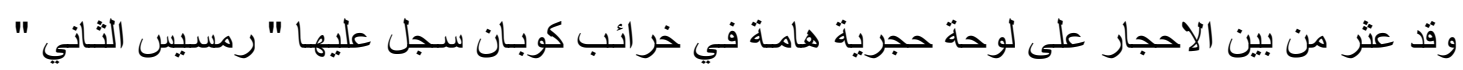

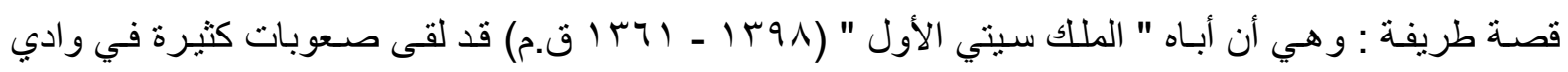
العلاقي نظراً لقلة المياه في ذلك الوادي ، وأنه قد اضطر الىى نقل كميات كبيرة من المياه على ظهور الحمير الى المناجم تكفي مئات من العمال الذين يعملون فيها وأن عملية نقل المياه كانت تكلفه الكثير من الجهد و المـال ، ور أى أن يحاول حفر بئر في ذلك الطريق المؤدي الى المناجم ، وقد تمت المحاولة وتم حفر البئر وعمل العمال

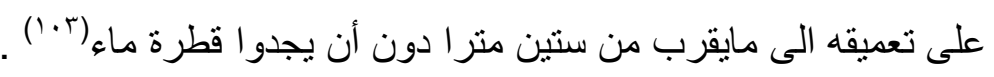

وقد تجمع العلمـاء ورجال البلاط حول الملك وتحدثو امعسه أن يبتهل الى الآلهة و استمر في الحفر

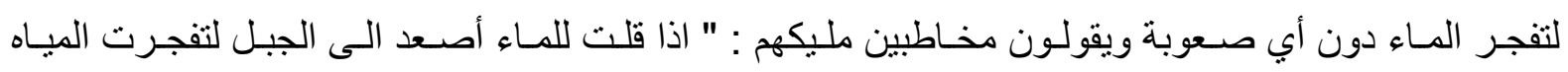

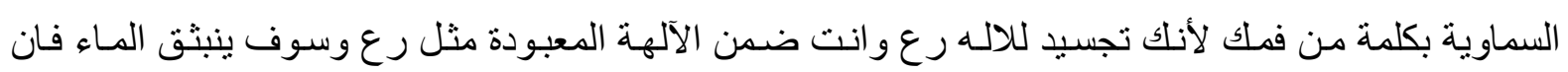

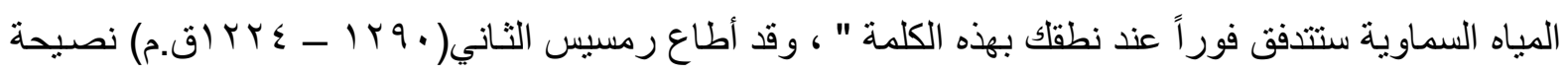
رجاله و علماؤه، وحدثت المعجزة وخرج الماء بوفرة من بئر تكفي آلآف العمال ، وقد حدثت هذه الاعجوبـة بعد

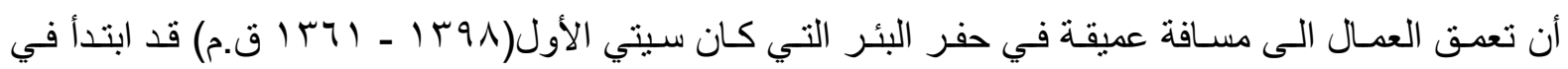
حفر ها"( - (1) .

وأن أكبر هذه المناجم وأعظمها إنتاجا هي مناجم " وادي مياه " أو " و ادي عبـاد "وقد حساول " سيتي "

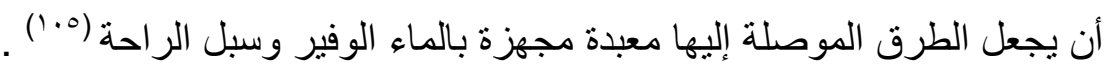

وقد وجدت خريطـة لمنـاجم الذهب بـو ادي " شـوانب " في ورقـة برديـة محفوظة بمتحف " تورينو"

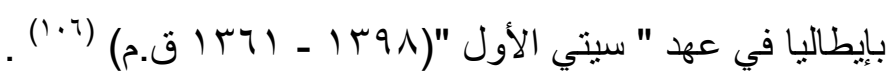

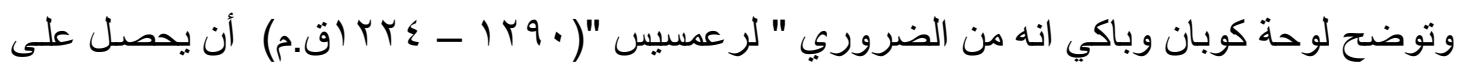
الذهب اللازم لتزين هذه المعابد ونقتهاو وعمل التماثيل ، وبخاصة إذا علمنا أنه قد صنع تمثالاً من الذهب لو الدهاه

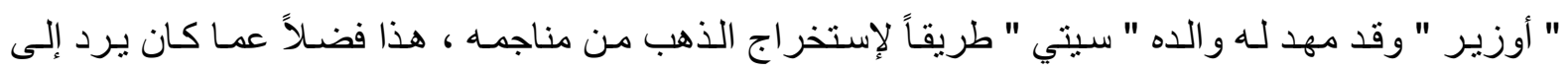

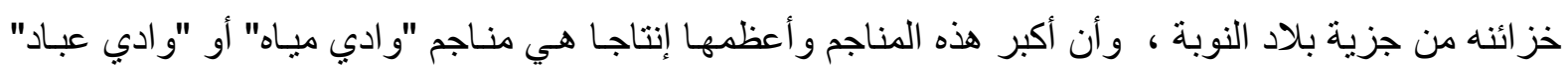

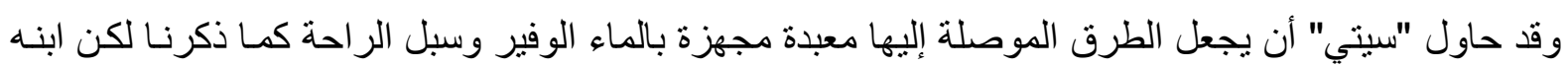
"رعمسيس"(†• •) قد حاول محاولة أخرى لتوفير المياه فيها ، فحفر بئر ا عميقة يتدفق منها الماء السـائغ للثـاربين

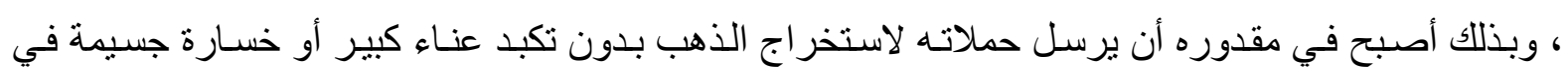

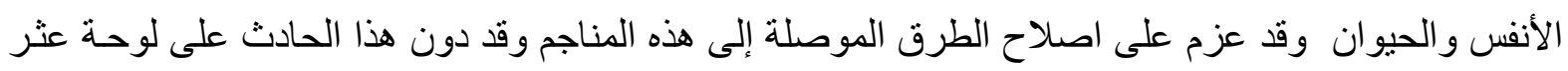


عليهـا في كوبـان ومـأتم بعد ذلك مـن إجر اءات على يد نائب بـلاد " كـوش " الذي وكلت إليـه هذه المهمهـة

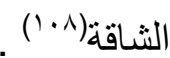

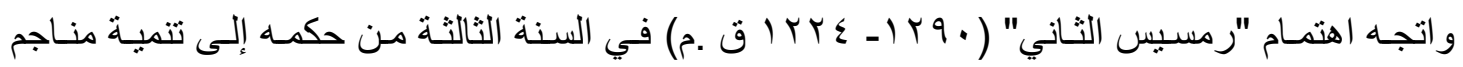

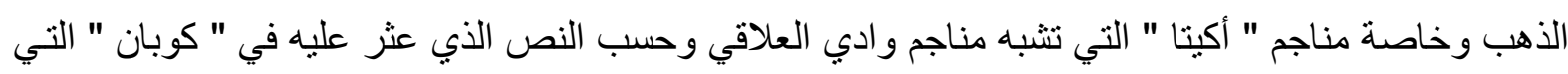

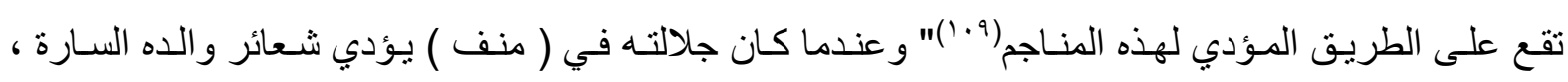
وشعائر آلهة الجنوب و الثمال بمقدار ما أعطوه من قوة ونصر وحياة طويلة تعد بعشر ات آلاف السنين حدث أنـه ذات يوم ( تأمل ) كان على عرش عظيم من السـام ( خليط من الذهب والفضـة ) (·"')، ومرتديا تاجـا ذا ريثتين ومعددا الممالك التي يأتي منها الذهب ، وواضعا خططا لحفر آبار على الطرق التي ينقصها المـاء ، بعد

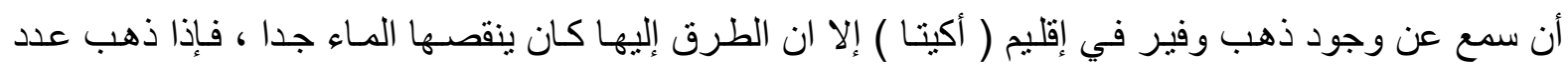
عظيم من رجال القوافل الذين ينظفون الذهب إلى هنالك ، كان لايصل إلا نصفهم ، لأنهم كانوا يموتون عطشـا

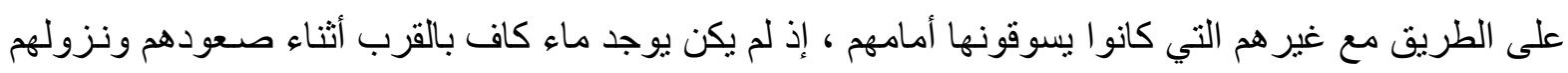

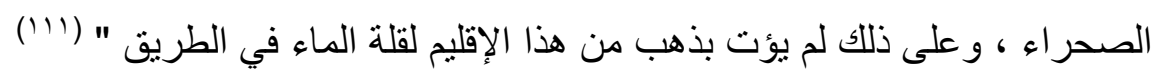
وأر اد جلالته من حامل الختم الملكي أن يدعو أمراء البلاط لكي يثـاور هم في أمر هذا الإقليم وكيف يمكنه اتخاذ الإجر اءات الضرورية بشأنه فأحضروا في الحال أمام الإله الطيب وشـاور هم الملك في خطة حفر

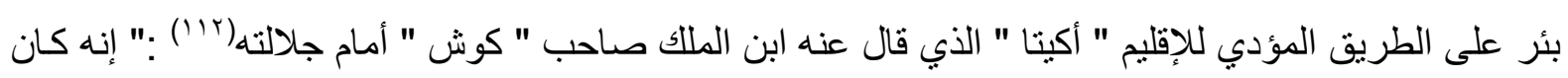
ينقصه الماء بهذه الكيفية ، فقد ماتوا ( أي رواده ) عطشى فيه ، وكل ملك قبلك رغب في فتح بئر هنالك ، ولكن لم يصب نجاحا ، وقد حاول ذلك الملك ( سيتي الأول ) وأمر بحفر بئر عمقها عشرون ومائة ذر اع في زمنهـ ، ولكنها نبذت على الطريق لأن الماء لم ينبع منها ، ولكن إذا تكلمت بنفسك لو الدك ( حعبى إله النيل ) و الد الإله

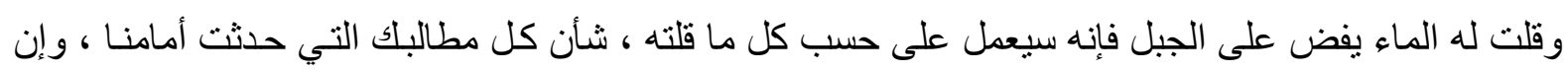
لم يكن قد سمع حديثها ، وذلك لأن والدك وكل الآلهة يحبونك أكثر من أي ملك كان منذ زمن ( رع ) " (r'l'). وقد حضر إنسان حاملا رسالة من ابن الملك صاحب " كوش " قائلا : " إن البئر قد انجزت ، وماقاله

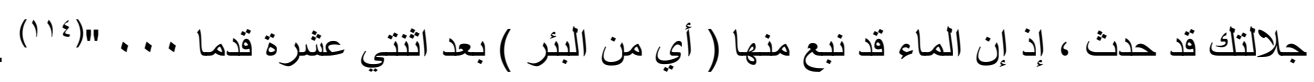
ومع هذا فكان انتاج الذهب في كوش أقل كثير ا عنها في واوات ؛ ولعل ذلك مرجعه لصعوبة الوصول إليها في كوش بالإضـافة إلى غنى منـاجم واوات في و ادي مروات ومنـاجم وادي قبقبـة وأم نبردى بينما منساجم

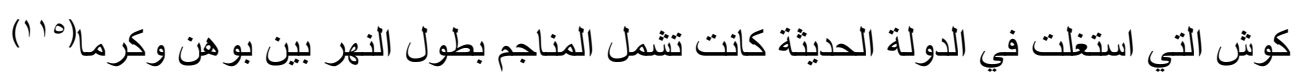
ونوجد وثثقة تذكر أسماء مناجم الذهب في النوبة كما في الثكل رقم( ( ) (1'(1) الني عرفها المصريون ، ويرمز لكل منجم بمائدة قرابين وكتب فوقها اسم المنجم و هذه الوثيقة نقشت على حو ائط معبد الأقصر من عصر

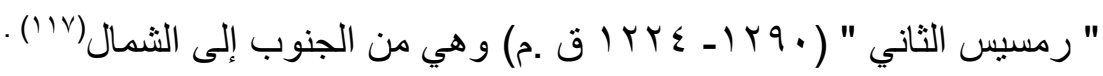

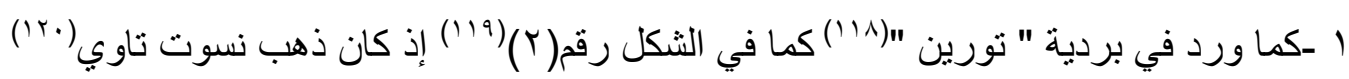


r-"عـروش الأرضيين " : وهو اسم جبـل " برقل "(1r')، وهذا الجبـل يوجد فيـه الذهب والأحجـار الكريمـة ويثمل جبل " البرقل " ، ومناجم " أبو حمد " في منطقة الجندل الرابع ، وقد سجل هذا المصدر للذهب بمعبد

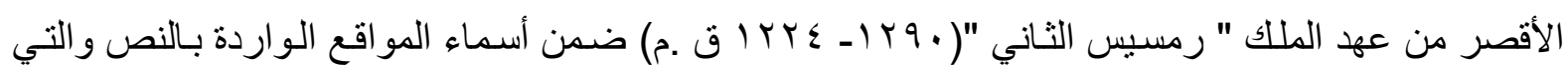

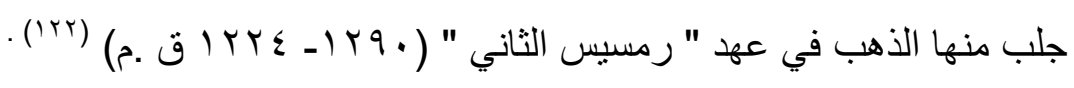

"ــ " ذهب " جبل عمو " " أي ذهب البلاد الجنوبية ": وهذا الجبل يشمل المنطقة الواقعة على ضفتي النهر بين صولب وكرما شمال وجنوب سابو عند الجندل الثالث(rrr) ، وسجل هذا المصدر للذهب بمعبد الأقصر من عهد

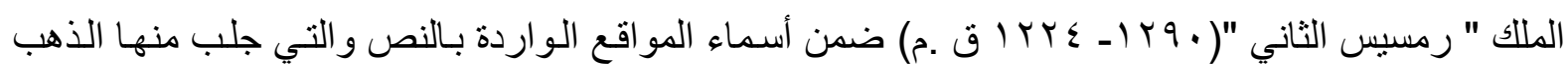

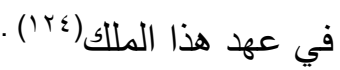

ع- - جبل كوش ويشمل المناجم قرب سمنة " جبل دوش " وهذه المنطقة حددها ريزنر بمنطقة كوش الواقعة

$$
\text { بين ساي وسمنة(ror) ) }
$$

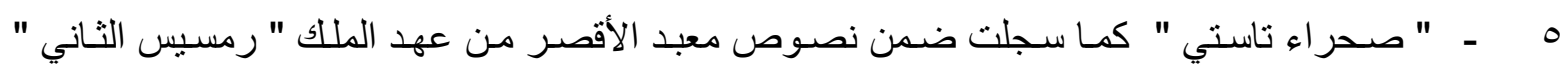

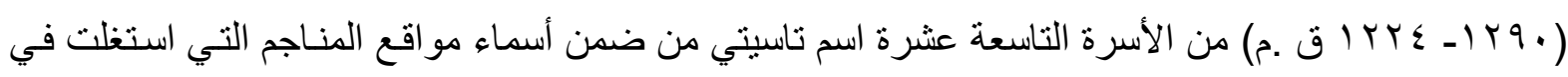

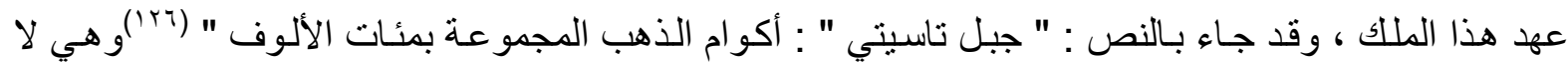
تتشمل فقط مناطق تنقيب الذهب شمال سمنة إنما امتد إلى جنوب الجندل الثناني وشملت منطقة واو ات وقد تكون تاستي بديلا لواو ات الذي قل استخدامه في عصر الدولة الحديثة ولذلك فهي تشمل المنـاجم الجنوبيـة من وادي وني العلاقي (IrV)

$$
\text { 7- ( جبل خنتى حن نفر ) إذ وجدت فيها مناجم قرب النيل(^^ا) . }
$$

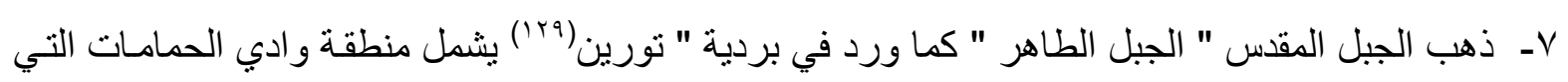
ذكرت في تللك البردية(·r).

ويقسم فركوتيه('اr) هذه المناجم إلى ثلاثة مناطق، ذهب كوش ويشمل (جبل برقل، وعامو عند الجندل الثاني، وجبل كوش قرب سمنة ، ومناجم سمنة مثل دوشـة)، وذهب واوات ويشـمل تاستي وخنتى حن نفر في و ادي العلاقي ووادي قبقبه وتثنمل( مناجم شمال سمنة ومناجم وادي العلاقي )، والثالثة ذهب قفط و ادفو. و أيضاءكان الحصول على مصادر الذهب في التاريخ الفرعوني في الاسرة التاسعة عشرة من منـاجم أكيتا وكاروى، وجبل البرقل، وصولب، وكرما، وبونت التي تقع بين أثثوبيا والسودان و" ذهب عمو" أي ذهب البلاد الجنوبية وكذلك مناجم الفواخير الذي كان يمكن الوصول إليه ضمن الطريق الذي يربط بين البحر الأحمر

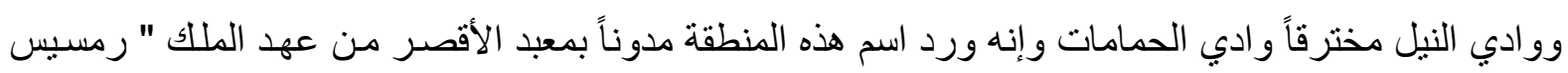

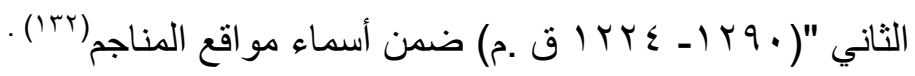

ومنـاجم أكيتـا في الجزء الأوسط من وادي العلاقي وورد ذكر هذه المنطقة لأول مرة مدون بلوحة

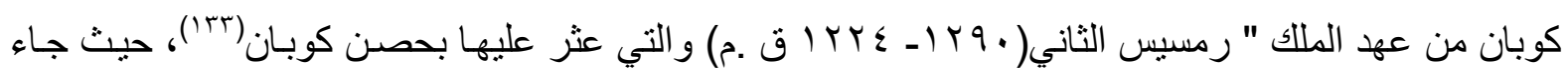


باللوحة " أن بعثة قد أحضرت الذهب من إقليم "أكيتا" ويعتقد أن "أكيتا " هي الأسم القديم لمنطقة من منـاطق مناجم وادي العلاقي إذ كانت تحمل هذا الاسم خاصة وأنه عثر على الجزء الباقي من اللوحة بو ادي العلاقي

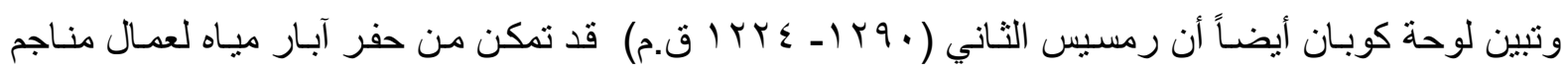

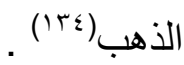

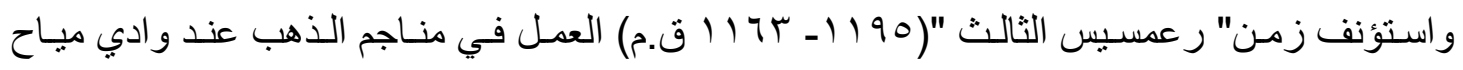
بصحر اء الثرقية ووادي العلا في نوبيا(roris ).

وتبين لفائف من بردية " تورين " و الموجودة حالياً في متحف المصريات بمدينة تورين بإيطاليا ، والتي

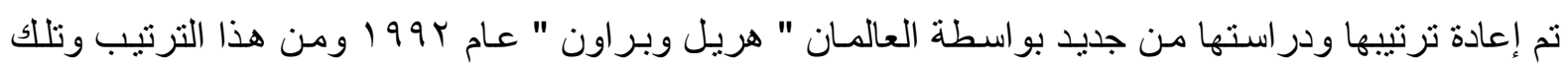

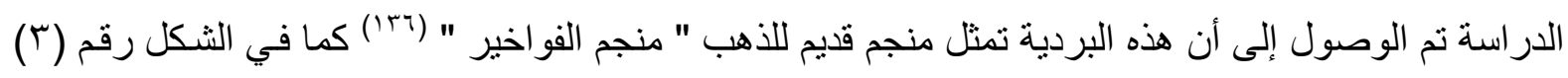

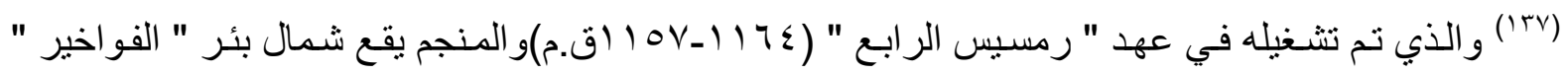

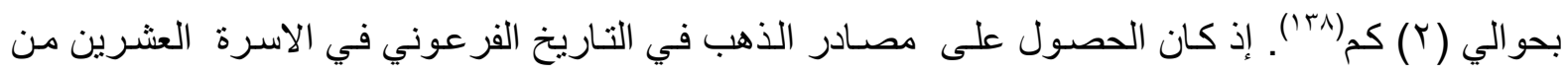
مناجم أرض العبيد(ج"). وبالتالي نجد منطقتين رئيسيتين لتعدين الذهب هي واوات وتضم وادي العلاقي ووادي قبقبه ، و الثانية منطقة المناجم قرب النيل بين بوهن وكرمـا وقد استخدم المصريون القدماء أنفسهم حيث فرقوا بين مناجم ذهب واوات من ناحيـة وذهب كوش من ناحية أخرى إذ تذكر حوليات " تحتمس الثالث " " ذهب

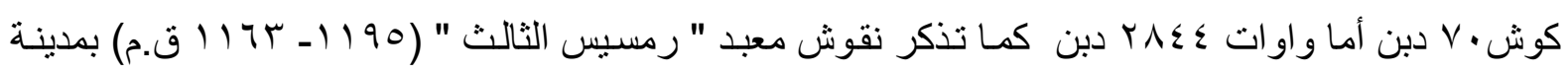
هابو " ذهب كوش " (. (1) ).

ومع هذا فكان انتاج الذهب في كوش أقل كثيرا عنها في واوات ؛ ولعل ذلك مرجعه لصعوبة الوصول إليها في كوش بالإضـافة إلى غنى منـاجم واوات في و ادي مروات ومنـاجم وادي قبقبـة وأم نبردى بينمـا منـاجم

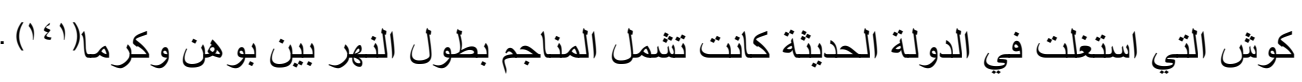

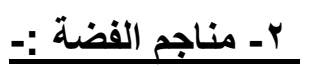

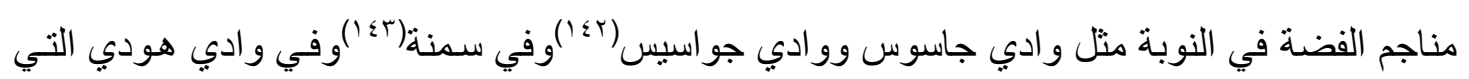

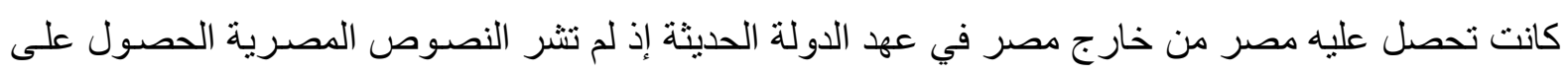

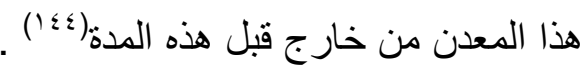

\section{ب- مناجم النحاس:-}

أن أهم مناجم النحاس التي وجدت في بـلاد النوبـة إذ وجد نقش نص من عصر الأسرة التاسعة عشرة

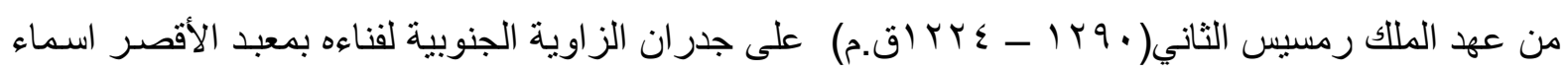

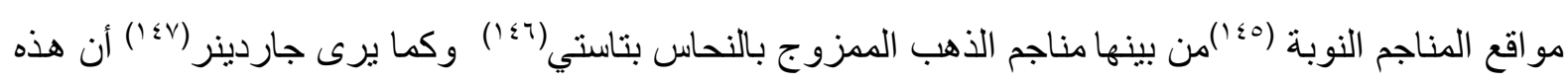

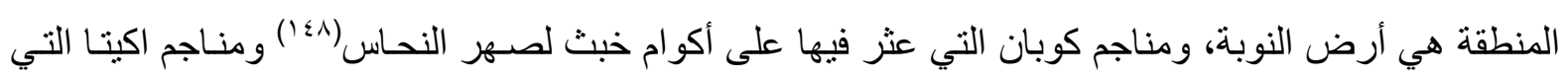

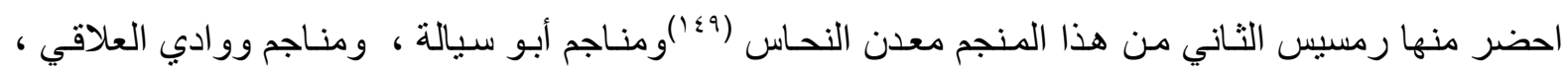

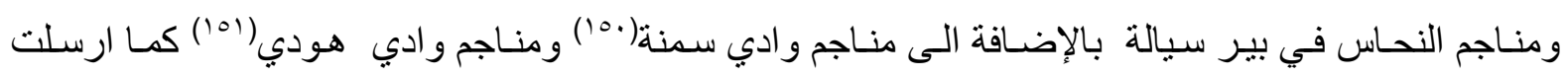


العديد من الحملات الى كوش هدفها البحث عن المعادن(م) أو أيضاً مناجم الصحر اء الغربيـة إذ يعد طريق درب

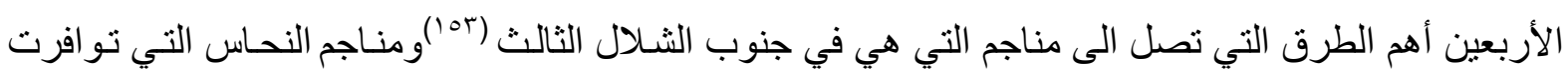

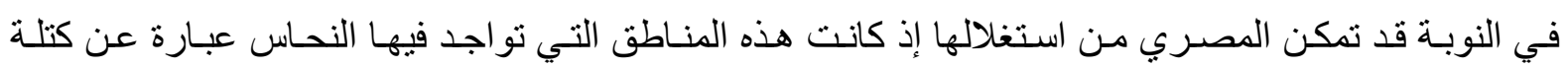

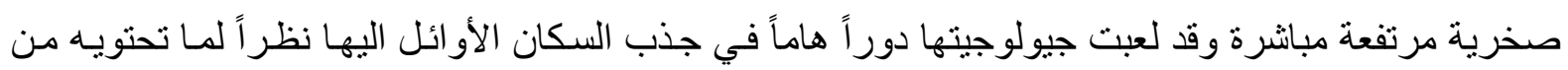

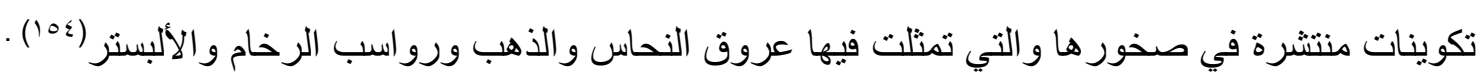
ويتضـح ممـا تقدم أهميـة المنـاجم النوبيـة في انتـاج الذهب لذلك حرص الفراعنة على استثمار هذه

المناجم التي كانت تمثل المصدر الرئيسي للخزينة المصرية .

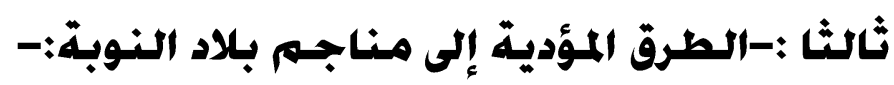

اهتم المصريون بأودية بلاد النوبة والصحر اء الثرقية و الغربيـة التي تؤدي إلى منـاجم الذهب كمـا هو

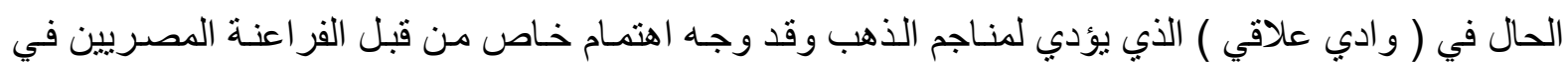

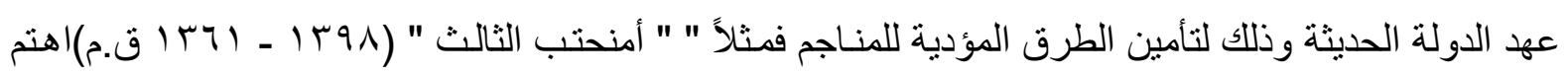

ببناء وتقوية الحصون في المناطق المؤدية للمناجم كحصن الدكة ليتحكم في طريق مناجم وادي العلاقي (100) . ا - الطريق المؤدي إلى منـاجم بـلاد النوبـة والصـحر اء الثـرقية هو درب الأربعين وهو من أهم الطرق على الإطلاق حيث مـامن طريق الا ومر بـه وهو طريق يبدأ من أسيوط على النيل إلى الواحات الداخلة ثم الخارجة مروراً ثم بمتد جنوباً حتى يصل إلى الثنال الثالث في النوبة العليا(107) . r- الطريق المؤدي للوصول إلى مناجم النحاس والذي يكون شمال سمنة وهذا الطريق البحري يبدأ من

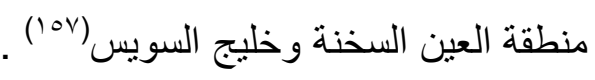
كـالفرع الثـمالي إلى و ادي سـنـة الذي يـربط منـاجم الذهب في وادي حمامـة وجضـامي ومنـاجم الرصـاص والذهب في جواسيس وكذلك مناجم النحاس في جبل دارهو وعربة(101). عـالطريق المؤدي إلى و ادي عباد في النوبة وكان سيتي الأول ةقد اهتم به وهذا الطريق يدخل الصحر اء مقابل أدفو (109).

هـطريق وادي " كاش " الذي يوصل إلى مناجم الحمامات كما أن في النوبـة طريق يعرف بطريق مجيف على امتداد جبل سفره ثم أبو مرود ثم أبو آسيا ووادي حمامـة وو ادي جمال وو ادي نجروس حتى يصل إلى لى مناجم الزمرد (17.) (17).

\section{رابعا-الأحسجار الكريمة وشبيه الكريمة التي وجدت في بلاد النوبة وأهميتها في مصـر:-} كانت تستعمل الأحجار الكريمة التي جلبت من بلاد النوبة في كثير من الصناعات ومنها صناعة الحلي فكانت الأساور والخلاخيل التي تحيط بالمعصم أو تلبس على الذراع لتصنع دائرة سحرية وكانت هذه الأسـاور

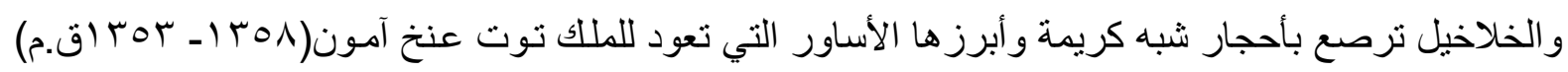

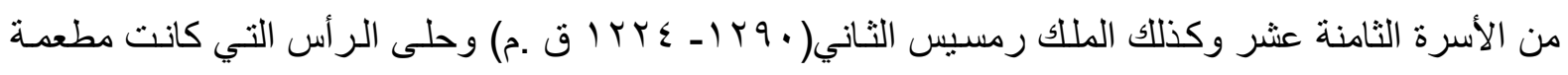




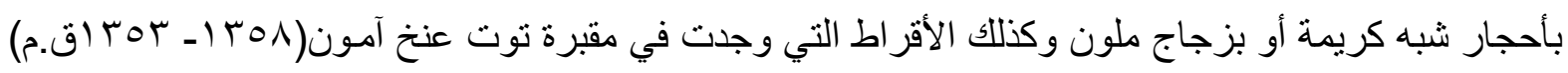

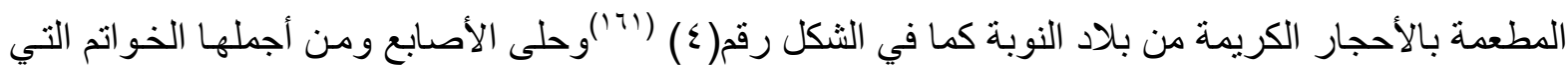

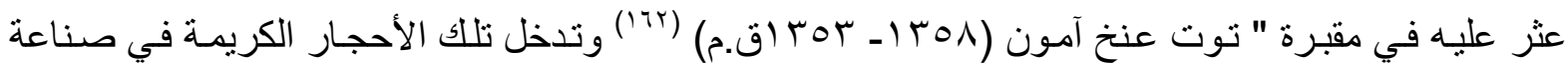
التمائم التي كانت تلبس كقلادة (rآ).

\section{1-العقيق ، والجزع ، وجزع العقيق:-}

كلها أنواع من الخلكيدوني المجزع أو المعرق وكل هذه الأحجـار منسوب بعضـها إلى بعض ، ويطلق

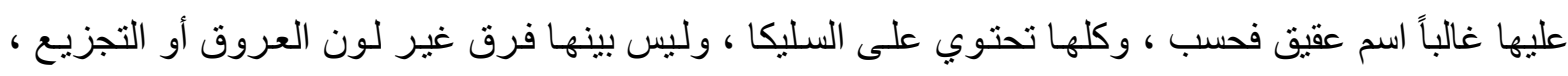

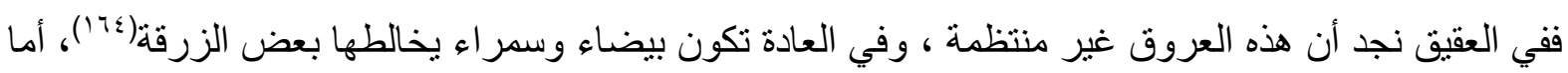
الجزع وجزع العقيق فنجد أن العروق مستقيمة ، ومنتظمة على وجه التقريب ، ويكون لون الجزع بنياً متبادلاً مع الأسود ؛ وفي جزع العقيق يكون الأبيض متبادلاً مع الأسمر المائل إلى الحمرة ويوجد العقيق في الصحر اء

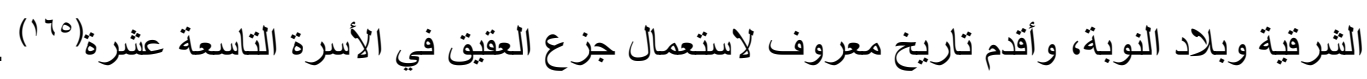

\section{r-السرد العقيق الأحمر " الكارنيليان " "Carnelian ".:-}

هو نوع من أنواع الكالسيدوني " السليكا " ، وترجع حمرته إلى وجود مقدار صغير من أوكسبد الحديد

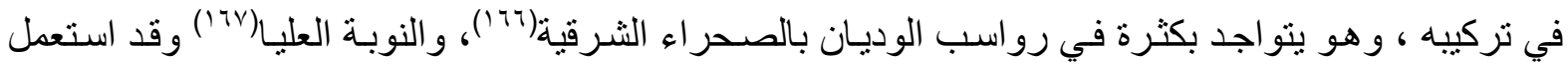

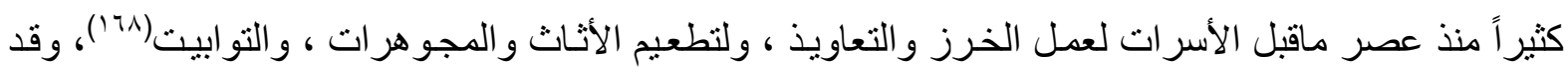

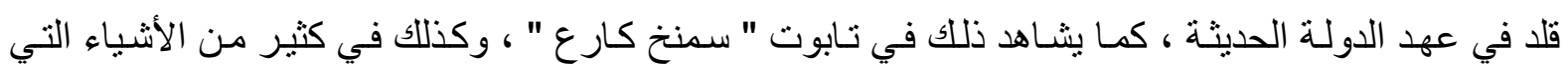

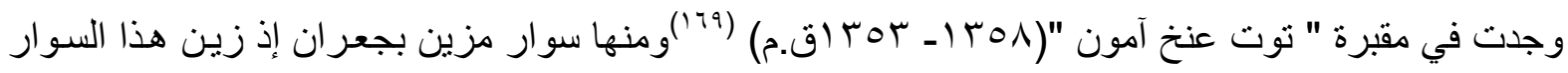

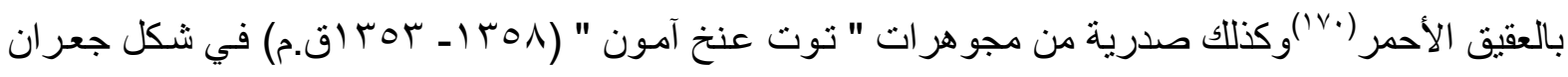

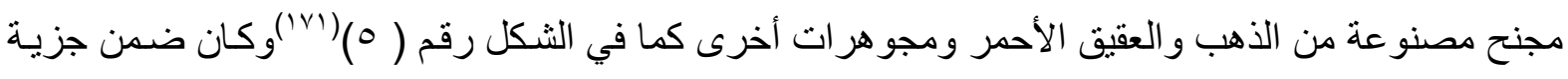

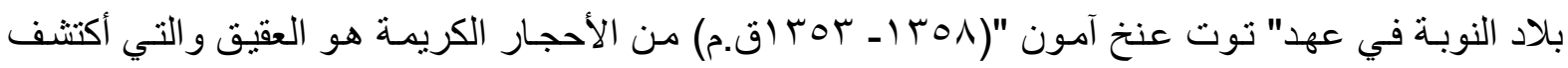

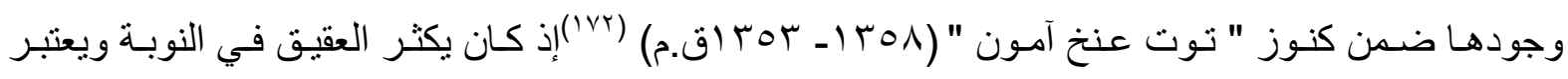
مصدر ا مهما في صنع المجو هر ات(

\section{-ب:Chalcedony}

العقيق الأبيض صورة من صور السليكا وهو شبه شفاف ذو مظهر شمعي فإذا كان نقياً فلونـه أبيض أو ضارب إلى الثهبة تشوبه زرقة خفيفة ويوجد العقيق الأبيض بالصحر اء الثرقية وأيضـاً وجد على بعد نحو

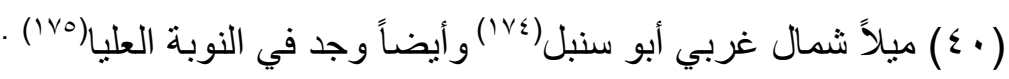

$$
\begin{aligned}
& \text { عـ أميثيست " (الجمشت " "Amethyst " }
\end{aligned}
$$

يتميز الجمشت بـاللون البنفسـي أو الأرجواني ويعزى هذا اللون إلى وجود عنصـر الحديد ، ويعد الأميثيست أحد أنواع معدن الكوارتز ويوجد ضمن عروق بجماتيت الكوارتز ، كما يوجد بالصـور البركانيـة في وادي نتش بالصحر اء الثرقية ، وكان يستعمل لعمل القلائد ، وكذللك الأساور ، وأحياناً تعمل منـه الجعارين 
و استعمل في عهد الدولـة الحديثة ، وظلت الجعارين تصنع مـن هذا الحجر حتى عهد " توت عنخ آمون "

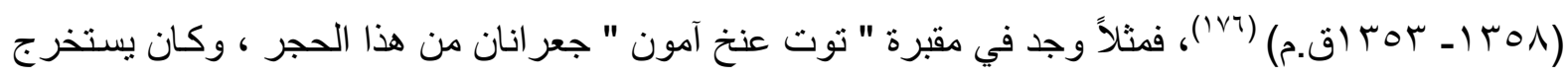
قديماً من جبل " أبو ديابة " ومنطقة " سفاجا " في الصحر اء الثرقية ، وكذلك عثر على مناجم لله على مسـافة (

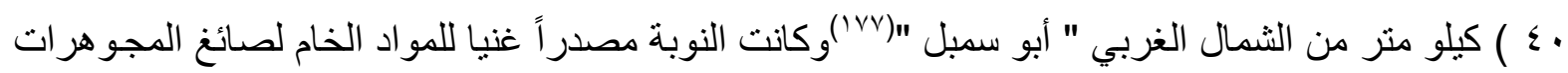

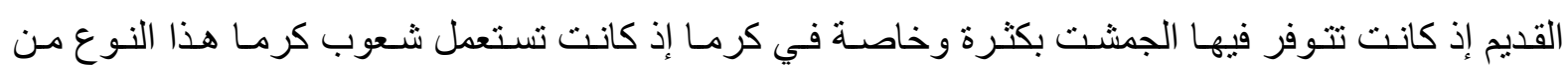
الحجر (IV^)

\section{هـ-Oألوبسيايان الأسود":Obsidian}

هو عبارة عن زجاج بركاني معروف منذ قديم الأزل ، و استخدم في صنع بعض الأدوات الحادة ، و الأوبسيديان نصف شفاف ، داكن اللون أو رمادي أو بني ، و الزجاج البركاني لا يوجد في بركانيات الأر اضي

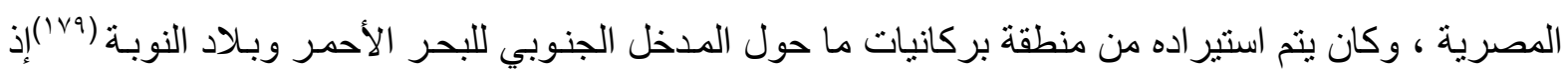
أستخدمت أحجار الأوبسيديان مع أحجار أخرى في في تشكيل العينين والحاجبين في القناع الذهبي " لتوت عنخ

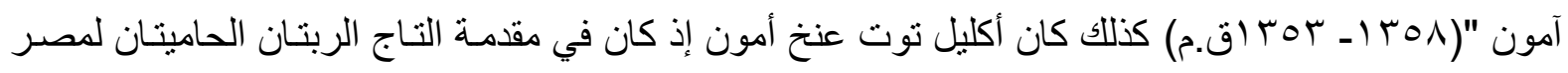

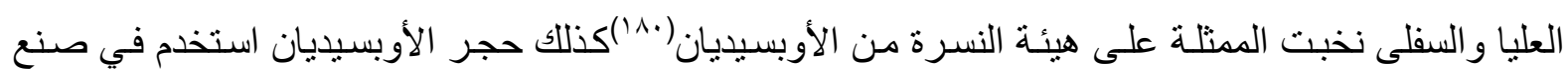
التمائم التي كانت تساعد ايقاف فعل السحر الثرير ('l').

\section{I-الزبرجد Olivine والزبرجد الأصفرPeridot:-}

الزبرجد سـليكات مزدوجـة مـن المغنسيوم و الحديـد ، ويكون شـفافاً أوشبه شفاف ولونـهـ عـادة أخضـر شاحب وقد وجدت ببلاد النوبة ، والزبرجد الأصفر وهو حجر شفاف ذو لون أخضر شـاحب مـاهو إلا صورة

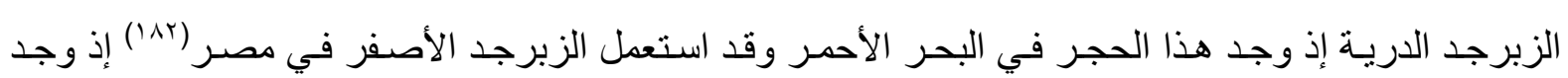

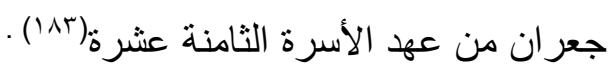
لا-Vاماثيست(ذو اللون البنفسجى):-

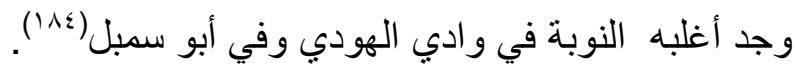

^-البلور الصخري:-

ووجد أغلبـه النوبـة في إذ كان يستخرج من محاجر أبو سمبل وكان الزجاج الملون والقيشـاني يقلد ويحل محل الأحجار في صناعة الخرز و التطعيم لعين الأنسان في التماثيل(هo') . خامسسا-البعثات التعدينية المصسرية التي ارسسلت إلى بلاد النوبة :-

ارسلت بعثات تعدينية في عصر الدولـة الحديثة إلى بـلاد النوبـة ومن هذه البعثات ماجـاء في مقبرة "

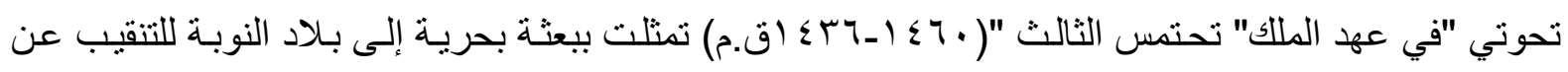

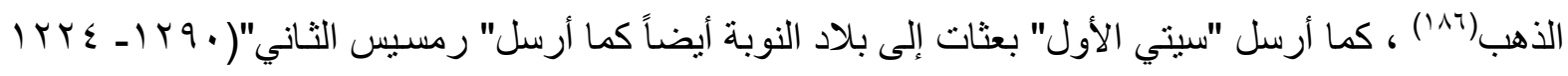
ق .م) بعثة إلى بلاد النوبة لتعدينه حيث سجلت البعثة لوحة في "عمارة غرب" يذكر قائدها أنه أنى بقدر كبير

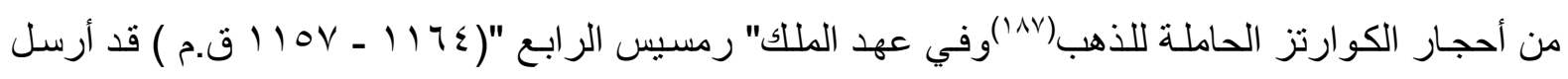


بعثة إلى بلاد النوبة ولم بعرف ناريخها وردت في بردية وقد وصلت هذه البعثة للتنقيب في أم سميوكي شرق وادي العلاقي (1^^).

\section{سـادسبا-التعدين المصسري في بلاد النوبة:-}

تشير النصوص المصرية إلى جهود المصري القديم في التعدين في منـاطق النوبـة والتي عدت من أهم أنشطة المؤسسة السياسية في مصر القديمة في عصر السرات وكانت لـه ادارة خاصـة توفر لـه كل احتياجاته وتضم عدداً من موظفي الخزانة ، وكانت هذه الإدارة تحت اشراف الملك نفسه وتذكر أن كل من أحمس الأول(

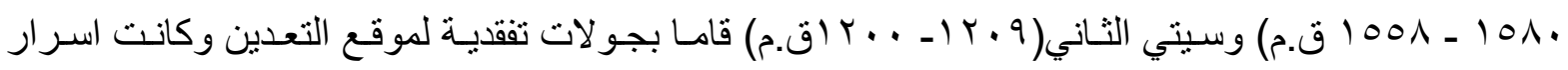

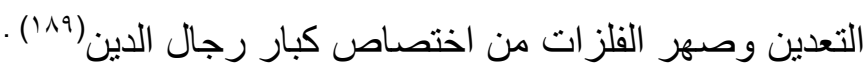

وبالتالي نجد منطقتين رئيسيتين لتعدين الذهب هي واوات وتضم و ادي العلاقي وو ادي قبقبه ، و الثانية منطقة المناجم قرب النيل بين بوهن وكرما وقد استخدم المصريون القدماء أنفسهم حيث فرقوا بين منـاجم ذهب

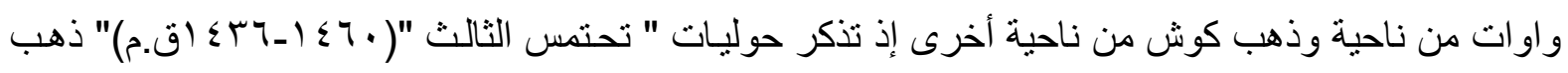

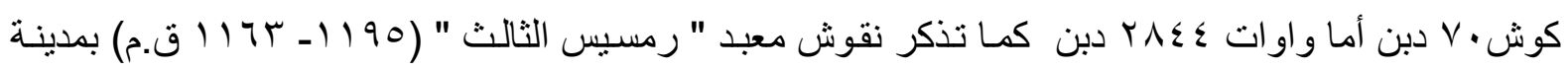

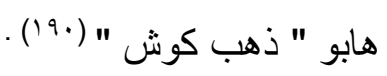

وقد بنى المصريون الأكواخ في النوبـة لاستغلال مناجمها ومحاجر هـا فقد اقيمت خمس قرى مبعثرة و وقابر و ابر اج مر اقبة إذ يدل تنوع المباني بأنها من عصور الفرعونيـة القديمـة والوسطى و الحديثنة وكانت هذه

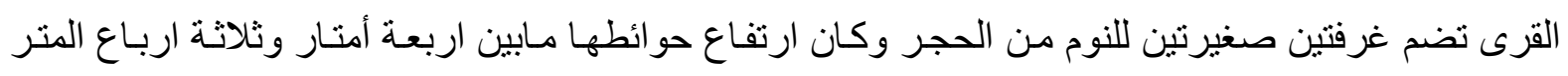
ولبعضها نو افذ صغيرة كما كان لبعضها اسقف وبعضها كهيئة مثلث رأسـه إلى الأعلى ، وقد اتصلت ببعضهـا

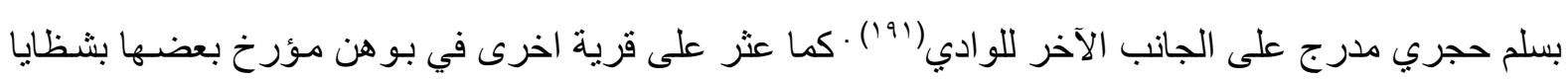
الأواني الفخارية من عصر الدولة الحديثة وقد كان للعمال المشتغلين بصـهر النحاس إذ عثر على خبثة وأفران

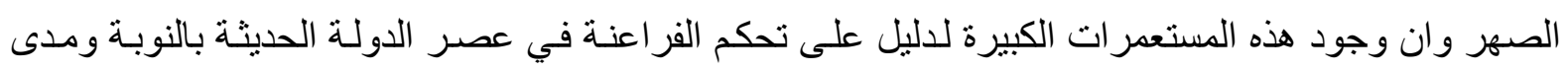

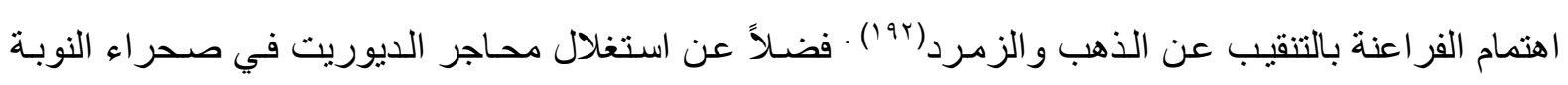

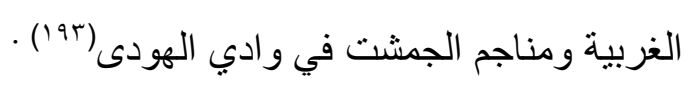

ويتبين من مواقع هذه الأكو اخ انه كانت تقام على التنال وكانت تستعمل للحر اسـة ومر اقبة العمل وقد بنيت في اودية شديدة الانحدار يجري ماء المطر اسفلها للاستفادة في غسل الذهب وكانت هذه كلها قريبـة من

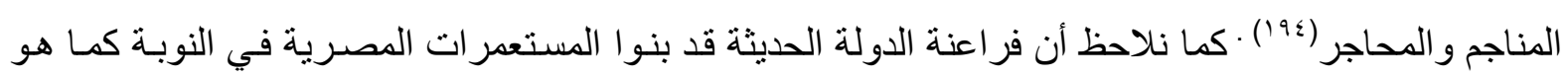
الحال في مدينة " سيسبي " وذلك لقربها من مصادر الثمينة إذ كانت هذه المدينة النوبية قريبة من رواسب كبيرة

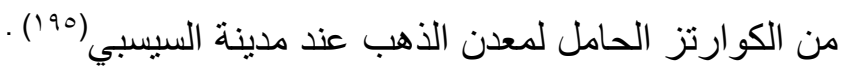

وقد ظهرت براعة المصريين القدماء في تعدين الذهب و الحصول عليه من موارده الطبيعية لذلك كانت

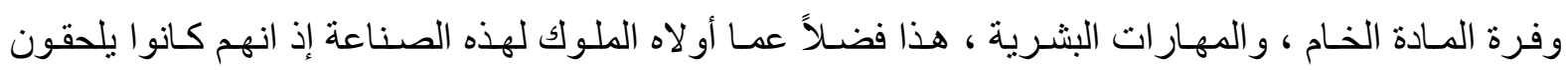


ببلاطهم صياغاً يعملون كموظفين لديهم ، إذ نسمع بين موظفي القصر عن " المشرف على صـهر الذهب " و "

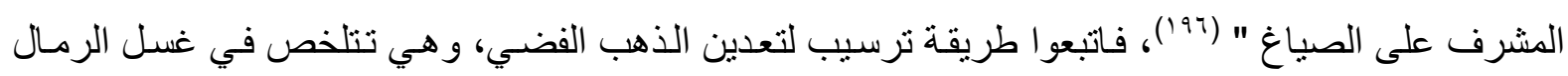
و الحصى التي تحتوي على الذهب بالماء الجاري الذي يحمل معـه المواد الخفيفة ، تاركاً حبيبات الذهب الثقيلة

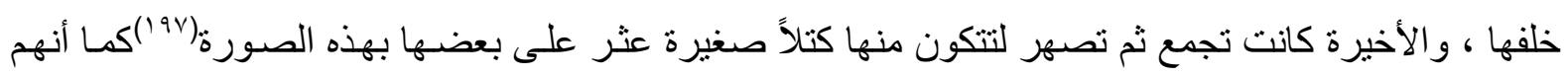
استخدمو ا طريقة أخرى لفصل الذهب من العروق الكوارتزيـة ، حيث كان الصخر يحطم بـالفؤوس ثم بحمل إلى خارج المنجم ، و هناك يفتت في أواني حجرية كبيرة حتى يصير مسحوقاً ثم يغسل بالمـاء فوق سطح مائل حتى ينفصل الذهب(191)

أن أهم ومعظم منـاجم الذهب القديمة في الصحر اء الصخرية في الناحيـة الثرقية معروفة ومن بينها منجم دويشـاتDuweishat الذي مـايز ال ينتج الذهب و اعتمدت العمليـة المستخدمة في استخر اجه على أخذ حبيبات الذهب من محلول معلق مكون من حبيبـات الكواتز المحملة بالذهب والمطحونـة طحنـاً جيداً وربمـا بطريقة مشابهة لتلك التي وصفت في تفاخر أحد الحكام المصريين بأنه جعل زعماء النوبيين يغسلون الذهب، وقد عثر على اعداد كبيرة من كرات الطحن الحجرية والبلاطات في الحصـون بالأضـافة الى المخازن المتسعة التي تجعلنا نعتقد على الأقل أن الأشكال النهائية في عملية استخر اج الذهب كانت تتم هناك (199)

الاستنتاجات

ا - كانت مصر تعتمد على المعـادن التي تحصل عليها من بـلاد النوبـة وخاصـة معدن الذهب بإعتباره

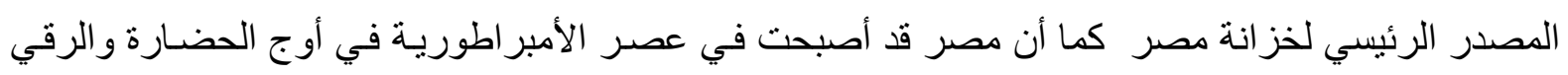
و الفتوحات وكل هذا يحتاج إلى مو ارد في خزانة الدولة لكي تغطي نفقاتها من البذخ.

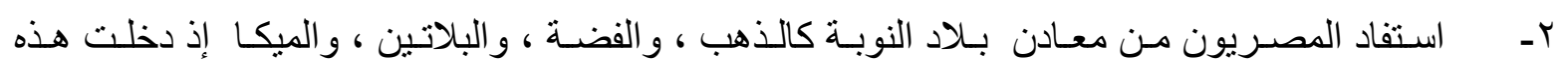

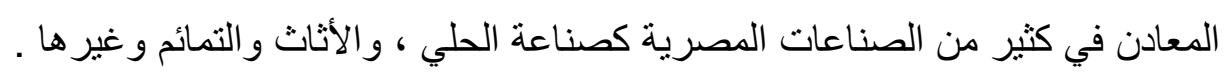
r- استثمار فراعنة الدولة الحديثة المنـاجم النوبية للحصول على معدن الذهب الثمين و المعـادن الأخرى وقد وجدت آثار تعدين في تلك المنـاطق أضـافة إلى توفير الميـاه في المنـاطق المؤديـة للمنـاجم من خـلال حفر الآبار في تلك المناطق الصحر اوية وتعبيد الطرق المؤديـة اليها وقد وصل فر اعنــة الدولـة الحديثة إلى الثـلال الرابع في النوبة العليا في استثمار المناجم الموجودة فيه .

\section{ع- اهنمام ملوك الدولة الحديثة بالطرق المؤدية إلى مناجم بلاد النوبة .}

ــ استعملت في مصر الكثير من الأحجار الكريمة التي وجدت في بـلاد النوبـة حتى أن الفراعنة ارسلوا

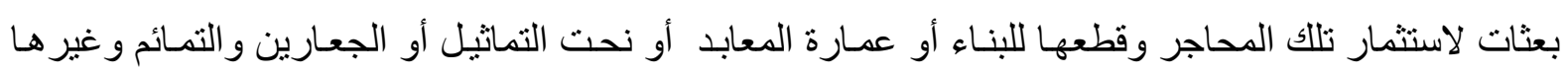
وكذلك استعملت الأحجار الكريمـة في صناعة الحلي والمجوهرات ووجد الكثير منها في مقابر ملوك الدولة 
ج- ارسل ملوك الدولة الحديثة البعثات التعدينية إلى مصر من إجل استغلال ثروات بـلاد النوبـة الطبيعيـة من الذهب و المعادن الأخرى وقد ذكرت العديد من النقوش بعثات التعدين التي قام بها ملوك الدولة الحديثة

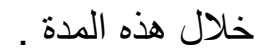

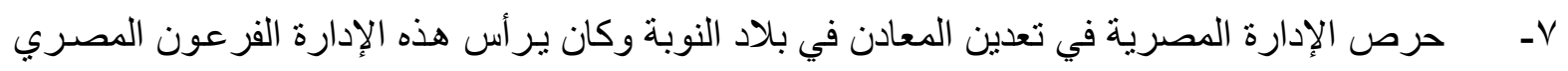
وقد وجدت عدة مناطق في بلاد النوبة اقيمت فيها مستوطنات مصرية وذلك لقربها من مصسادر المعادن الثمينة مثل بو هن إذ وجدت فيها آثار صهر النحاس ، وسيسبي التي شيدها الملوك في عصر الدولة الحديثة لقربها من مناجم الذهب . n من

\section{الملاحق:-}

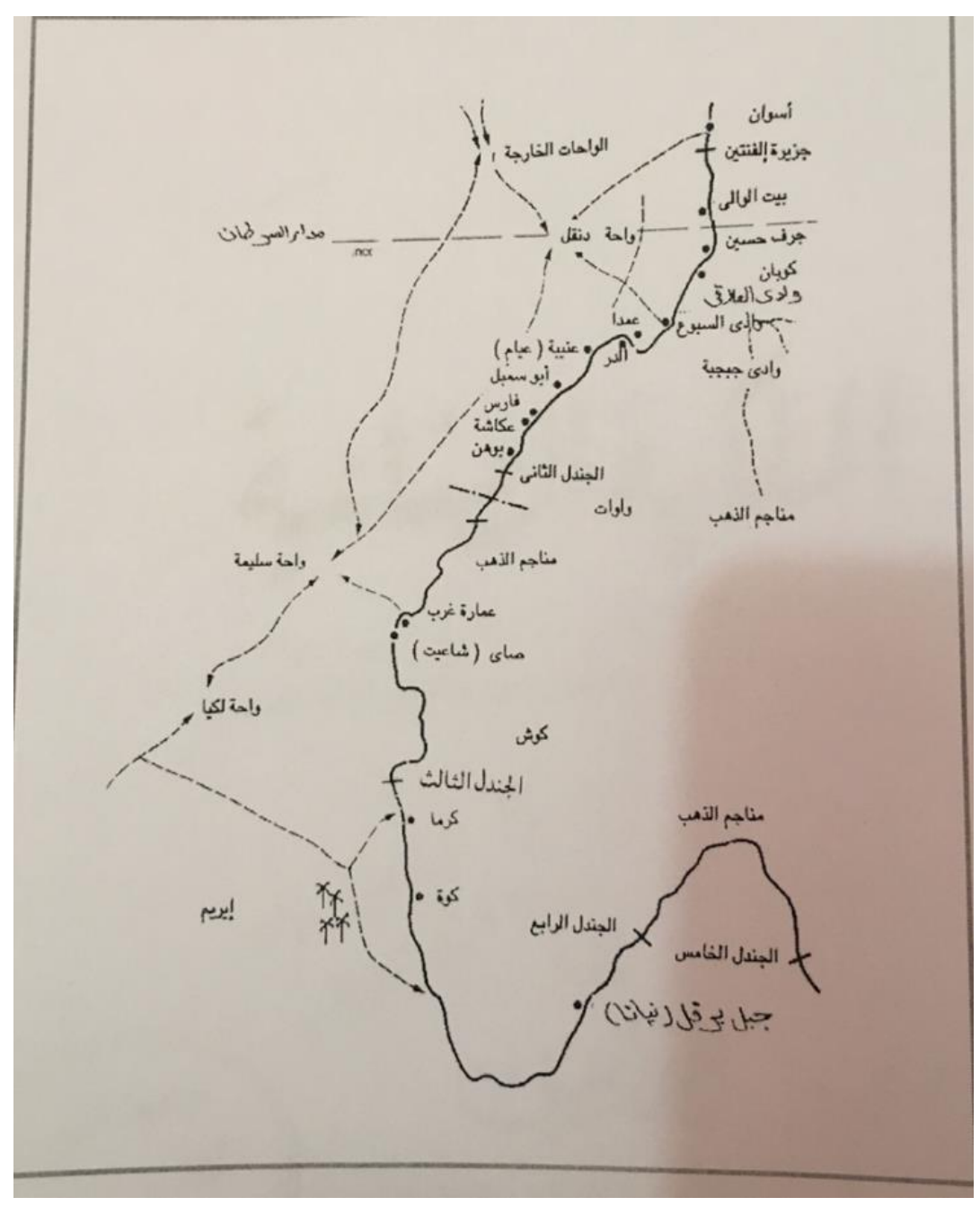

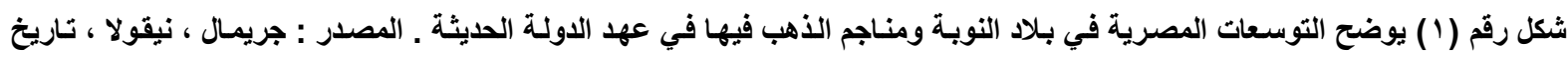

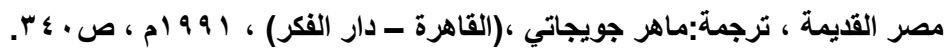




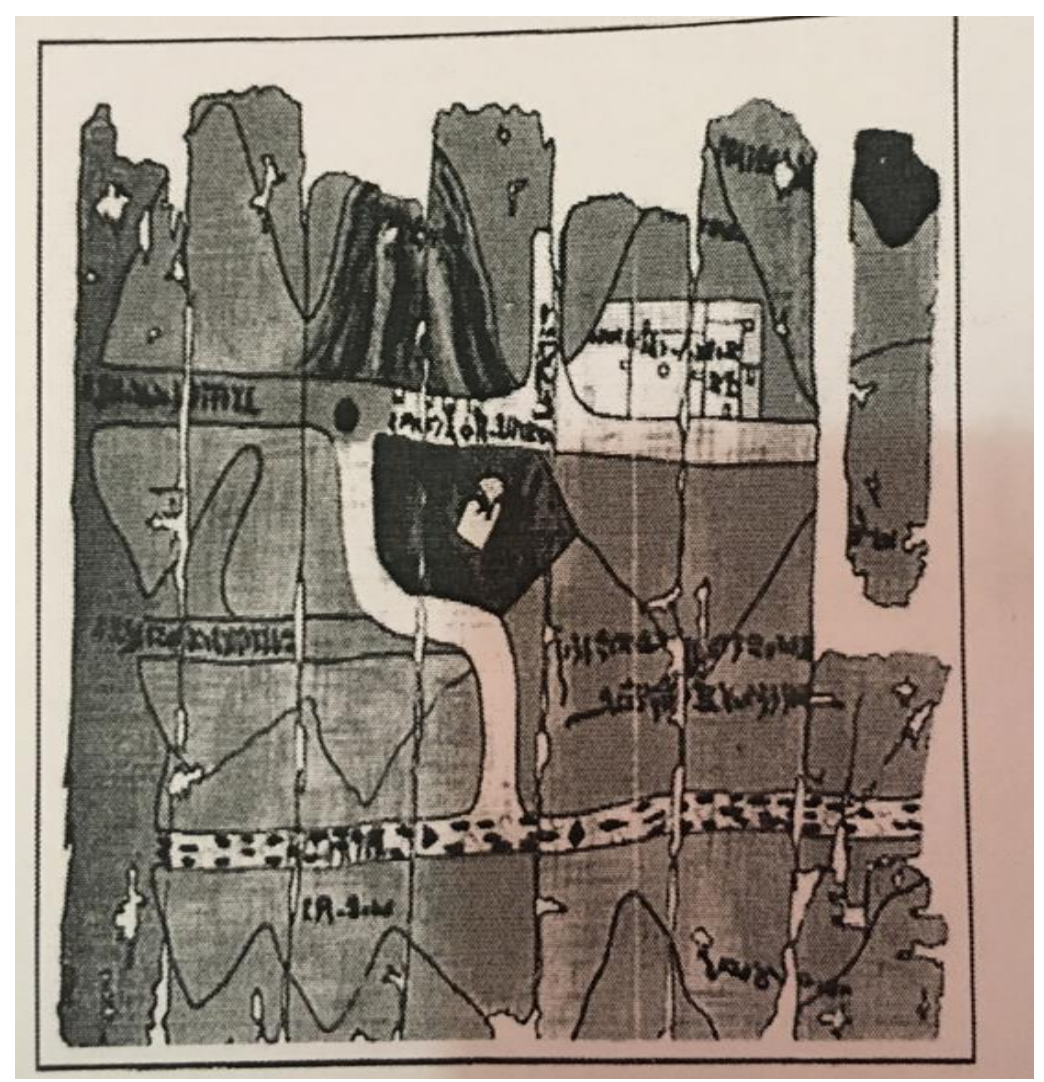

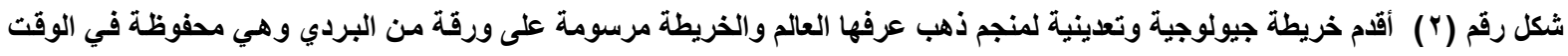

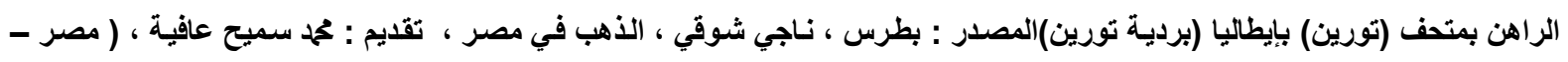

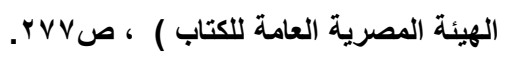

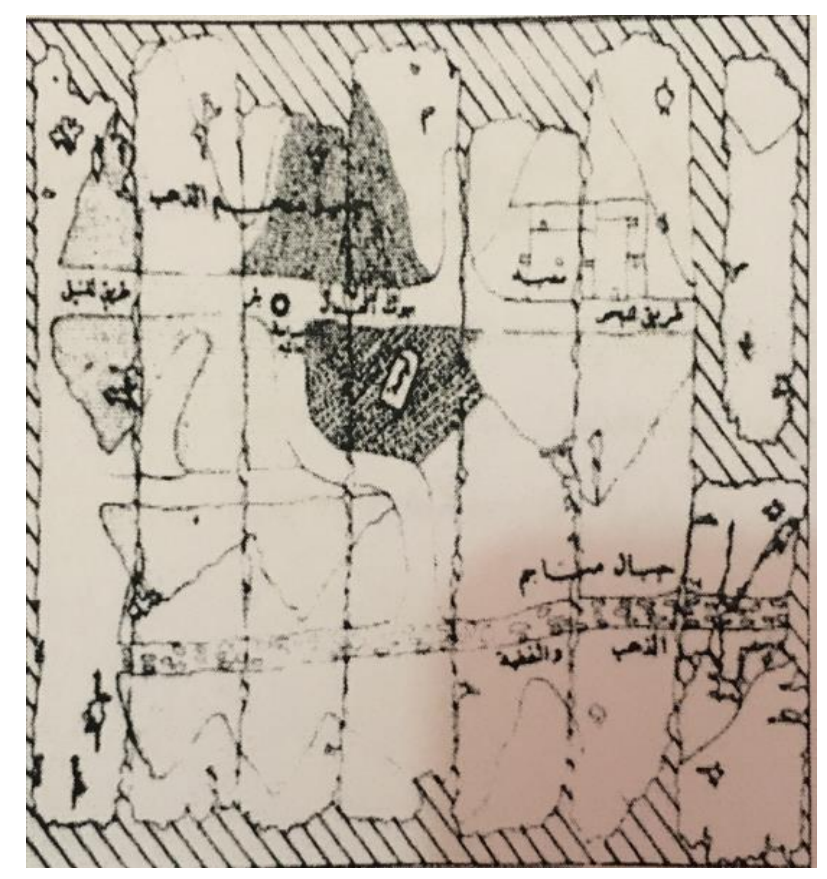

Editor, G.Mokhtar,General : شكل رقم (َّ) خريطة توضح منجم " الفواخير " ومـا حوله في بردية تورين المصدر

History Of Africa .II Ancient Civilizations of Africa, P. rVr. 


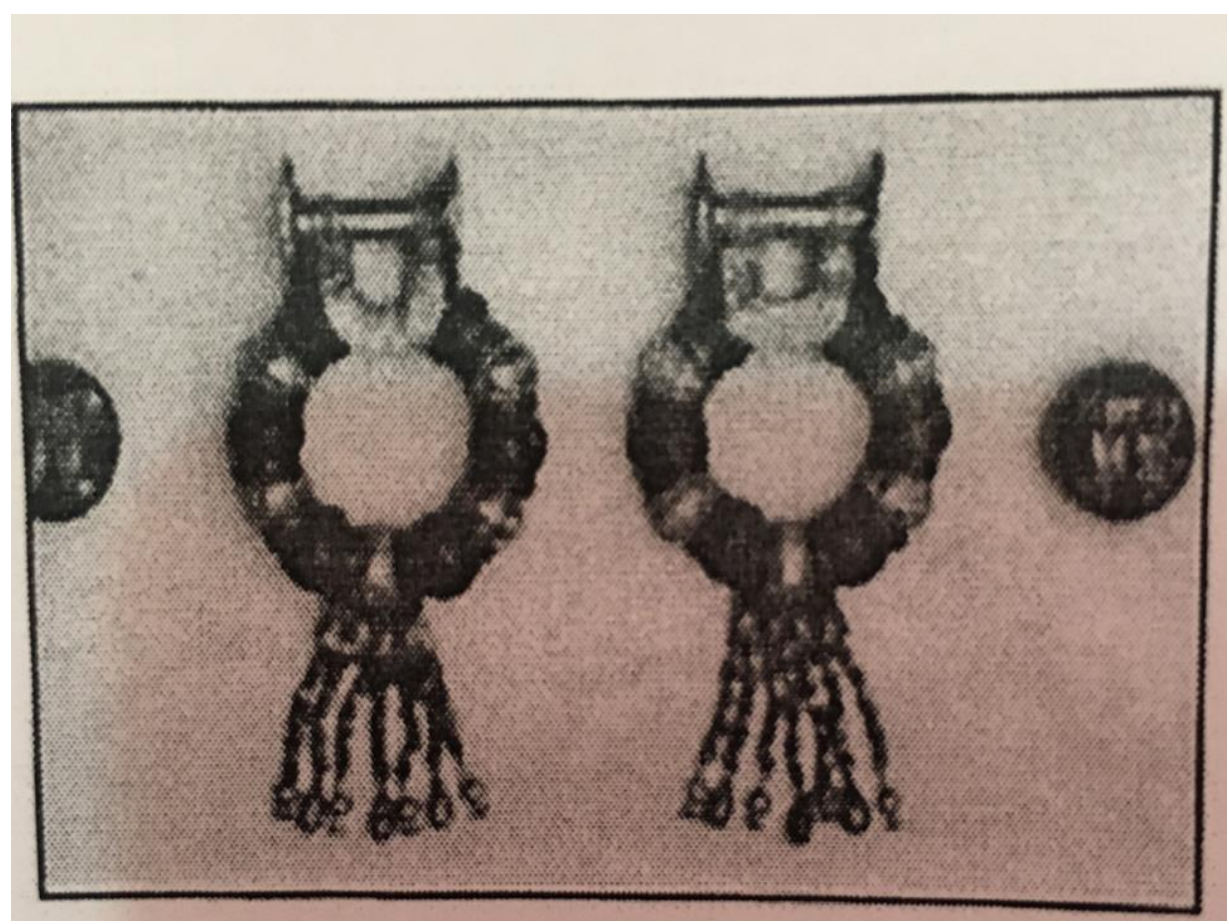

شكل رقم (؛) اقراطوجدت في مقبرة توت عنخ آمون الاريد ، سيريل ، مجوهرات الفراعنة ، ترجمة : مختار السويفي ، تقديم :

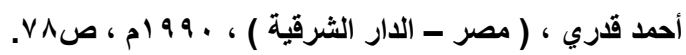

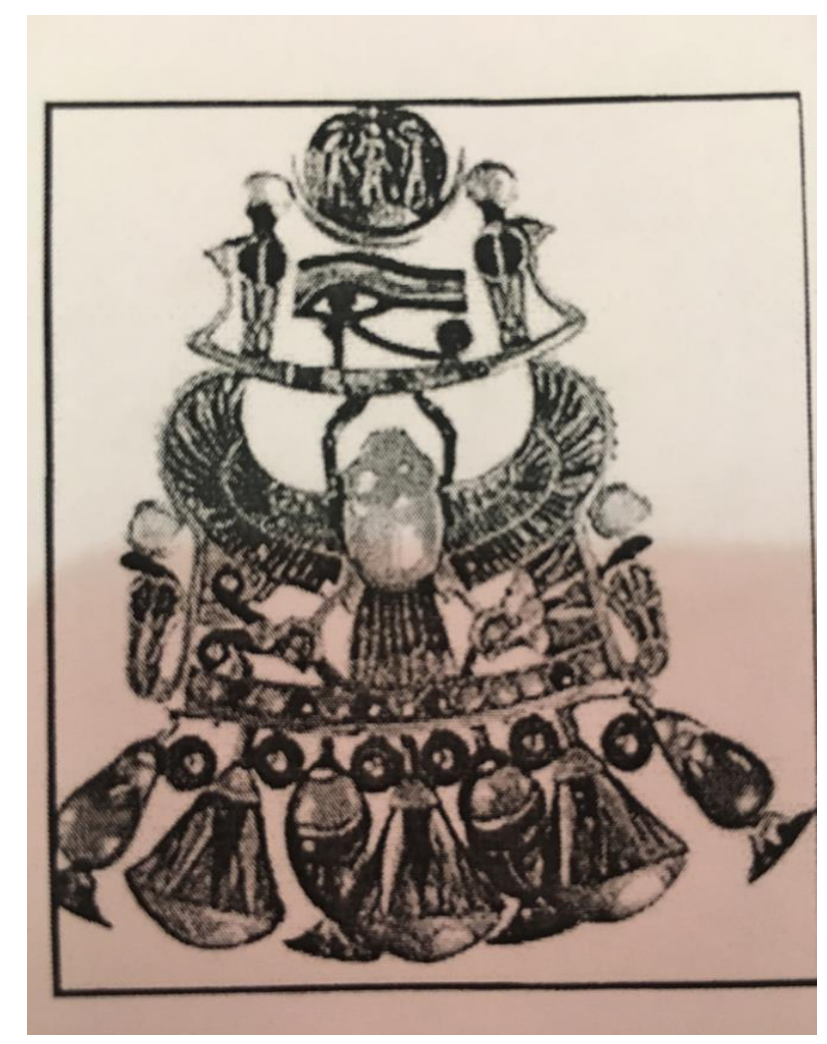

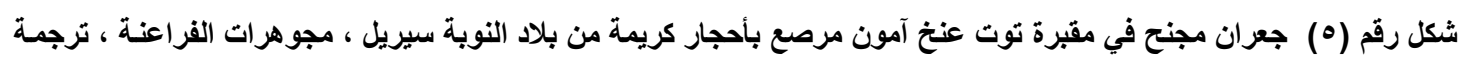

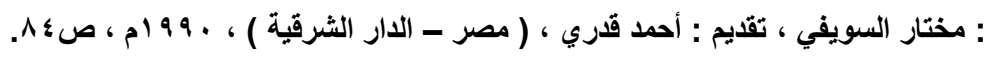




\section{الههوامشث:

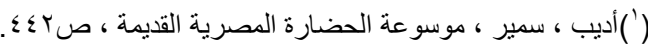

$\left({ }^{r}\right)$ Reisner, G. , Excavations Kerma HAS.VI, Cambridge, $19 r r$,PP. orv _ or^.

$\left.{ }^{r}\right)$ Haycock Bryan .G , The foreign relations of the Napatan - Meroitic Kingdom in the Sudan From the $\wedge^{\text {th }}$ Century B.Cto the $\varepsilon^{\text {th }}$ Century A.D , theses Durham University, 1970, P. rᄉ.

$\left(^{\S}\right)$ Editor, G.Mokhtar,General History Of Africa .II Ancient Civilizations of Africa, Heinemann. Calfornia.Unesco, 1911, P. r $Y r$.

$$
\begin{aligned}
& \text { ( ) لوكاس ، الفريد ، المو اد والصناعات عند قدماء المصريين ، ترجمة : زكي اسكندر ، ( مصر - مكتبة مدبولي ) ، ص آب - صبr؟ب. } \\
& \text { (") سبنسر ، نيل ، وآخرون ، مدينة عمارة غرب المعيشة في النوبة الفرعونية ، صعه . }
\end{aligned}
$$

(')Breasted .J.H, Ancient Nubia Press Kit, The Museum of the Oriental lnstitute at the University of Chicago, February, ץ.. T, PP. \&-V.

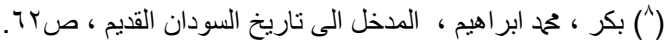

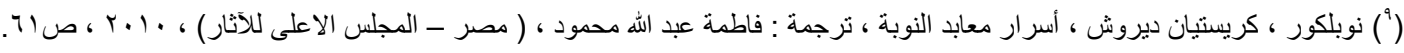

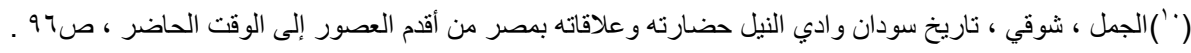

$$
\begin{aligned}
& \text { (") خليل ، عبد المجيد حسن ، النوبة الإنسان والتاريخ ، تقديم : فريدة النقاش ، ( مصر - مكتبة مدبولي ) ، صبr. }
\end{aligned}
$$

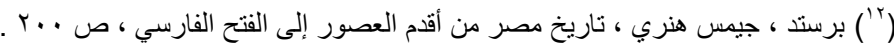

${ }^{(r)}$ G.Mokhtar,General History Of Africa .II Ancient Civilizations of Africa ,P. rVr.

(') G.Mokhtar, P. YVr.

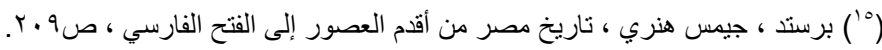

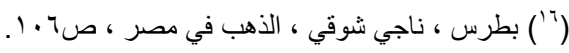

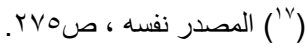

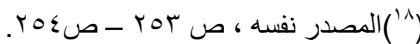

$\left({ }^{19}\right)$ Editor, G.Mokhtar,General History Of Africa .II Ancient Civilizations of Africa, P. rVr.

(r.) Darnell .John, The Stela of the Viceroy Usersatet (Boston MFA rorrrr), his Shrine at Qasr Ibrim, and the Festival of Nubian Tribute under Amenhotep II,Prs).

(") Darnell .John, P. r .

$\left(^{r r}\right)$ Harkless , Necia Desiree, Nubian Pharaohs And Meroitic Kings The Kingdom Of Kush,P. 119.

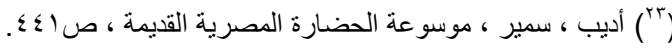

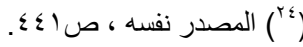

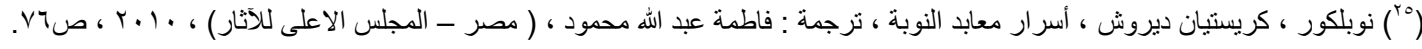

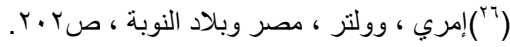

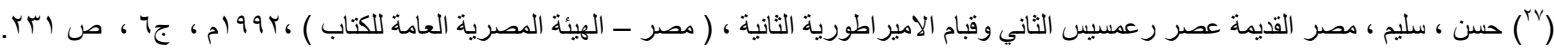

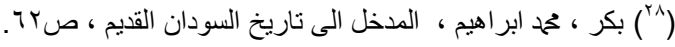

$\left({ }^{\uparrow q}\right)$ Joyce L . Haynes, Nubia Ancient King Doms Of Africa, p . $\Sigma \vee$.

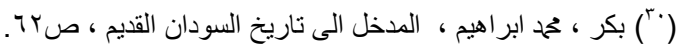

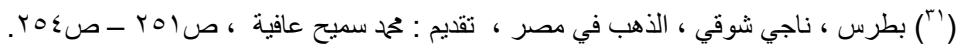

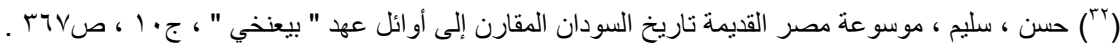

$\left({ }^{r}\right)$ Editor, G.Mokhtar,General History Of Africa .II Ancient Civilizations of Africa,P. $\Upsilon \vee \varepsilon$. 


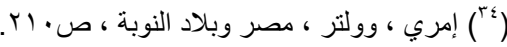

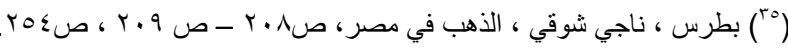

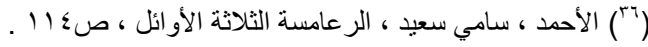

$\left({ }^{r v}\right)$ Harris ,J.R,Lexicographical Studies in Ancient Minerals,Berlin, 197$)$,P. $\left.८\right)$; Lucas ,A and Harris ,J.R,Ancient Egyptian Materials and Industries, London, 197 r, P. Y $\leqslant 0$.

$\left({ }^{\top \wedge}\right)$ Wilkinson , R.H , Symbol Maglc in Egyptian Art ,London, 199 \&, P.^r.

$\left({ }^{r q}\right)$ Hornung,E,Der Agytische Mythes der Himmelskuh,Leipzig , $19 \wedge r$,P.r ${ }^{\top}$.

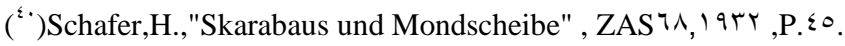

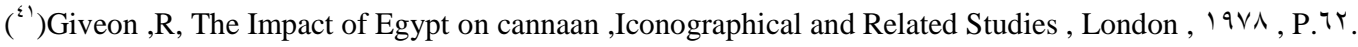

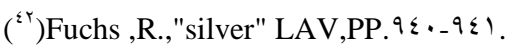

$\left({ }^{\xi r}\right)$ Joyce L . Haynes, Nubia Ancient King Doms Of Africa, p . $\leqslant \vee$.

(4؛) برستد ، جيمس هنري ، تاريخ مصر من أقدم العصور إلى الفتح الفارسي ، صو •r ؛ الجمل ، شوقي ، تاريخ سودان وادي النيل حضارته وعلاقاته

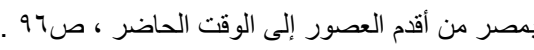

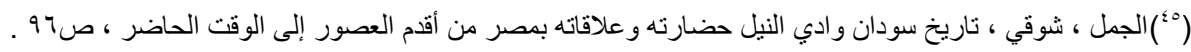

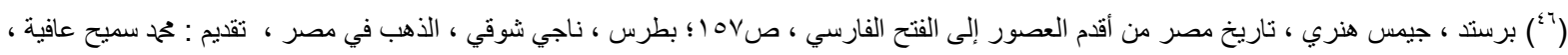

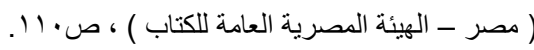

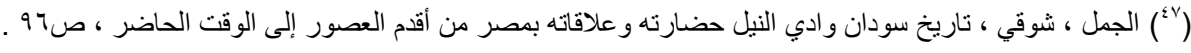

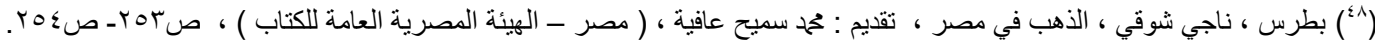

$$
\begin{aligned}
& \text { (99 ) شقير ، نعوم ، تاريخ السودان ، تحقيق : محم ابر اهيم أبو سلبم ، ( بيروت دار الجيل )، صلا } 1 .
\end{aligned}
$$

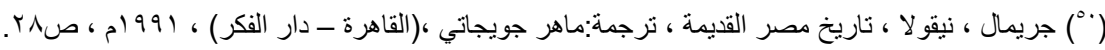

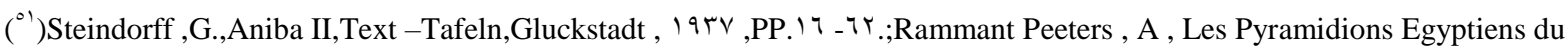
novel empire, O L A ' ', Leuven, 191 个, P.90.

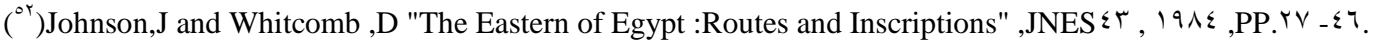

$\left({ }^{\circ r}\right)$ Forbes ,R.J , Studies in Ancient Technology, Vol ,Leiden, $197 \varepsilon, P .17 r$.

$\left({ }^{\text {\& }}\right)$ Harris ,J.R,Ancient Egyption Materials and Industries $\varepsilon^{\text {th }}$ Edition, London, $197 r, P . \varepsilon \wedge r$.

(10) عافية ، محمد سميح ، أضواء على استخراج واستخدام المعادن والأحجار عبر الحضارات ،( مصر - الهيئة المصرية العامة للمساحة الجيولوجية

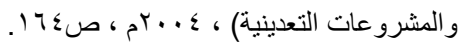

$\left({ }^{\circ}\right)$ Breasted , J.H , Ancient Records of Egypt, $19 \wedge 1$, II ,PP. $\leqslant \leqslant V-\varepsilon V 1$.

$\left({ }^{\circ \vee}\right)$ Vassilika ,E, "Egyptian Bronze Sculpture Before the Late Period",London, $19 \vee \mathrm{Y}$, P.^०.

$\left({ }^{\circ \wedge}\right)$ Hill , M "A Bronze Statuette of Thutmos III , The Metropolitan Museum of Art Journal rV, $199 \mathrm{~V}$, ,P.77.

$\left({ }^{\circ 9}\right)$ Emery ,W.B , A Prelimnary report on the Furst dynasty copper treasure from north Saqqara ASAE, 19 १, P. $\leqslant$ r .

(") Emery ,W.B ,P. $\leqslant \varepsilon$ r.

(")Vassilika ,E, "Egyptian Bronze Sculpture Before the Late Period",London, I $9 \vee Y$, P.^०.

$\left({ }^{\top r}\right)$ Vassilika ,E , , P.^v.

( $\left.{ }^{\top \top}\right)$ Breasted , J.H ,Ancient Egyptian Jewelry Best Selection from the Egyptian Museum,P. 17 .

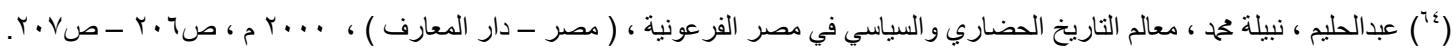

$\left(^{10}\right)$ Coghlan , H.H , Some Fresh Aspects of the Prehistoric Metallurgy of Copper, The Antiquaries Journal, XXII, $19 \leqslant$ r, P. $r \varepsilon$.

$\left(^{\top}\right)$ Ball .J , The Geog and Geol of South Eastern Egypt, P.ror. 


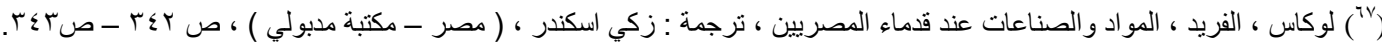

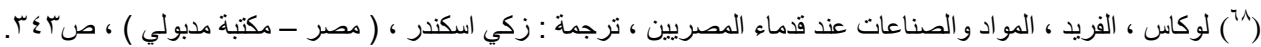

$\left({ }^{79}\right.$ Emery ,W.B,Egypt Exploration Society Preliminay Report on the excavations at Buhan, 19 \ , Kush ,XI, 1947 , PP. 117 ـ ir.

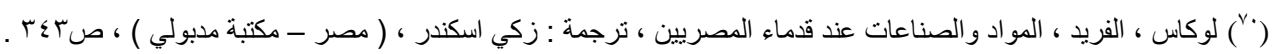

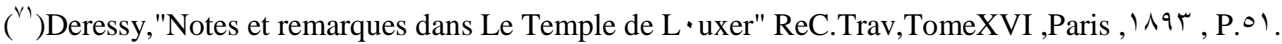

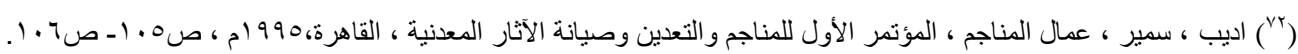

$\left({ }^{\vee r}\right)$ Gardiner , A.H ,Ancient Egyptian Onomastica, Vo 1,11 ,Xoford , 19 9 V , P. .

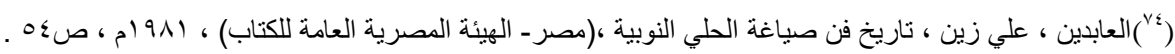

$\left({ }^{10}\right)$ Breasted , J.H , Ancient Records of Egypt , $19 \wedge 1$,II , P. $\leqslant \vee r$.

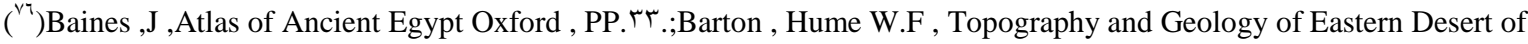
Egypt Centeral, London, $19 \cdot \mathrm{V}, \mathrm{PP} .1 \varepsilon_{-} 10$.

$\left({ }^{\vee v}\right)$ Barton ,Hume,W.F ,Topography and Geology of Eastern Desert of Egypt Centeral, London, 19.V, PP.। $1 \varepsilon-10$.

$\left({ }^{v \wedge}\right)$ Breasted , J.H , Ancient Records of Egypt , $19 \wedge \wedge$, II ,PP. $\leqslant \leqslant \vee-\varepsilon V /$.

$\left({ }^{\mathrm{rq}}\right)$ Baines ,J ,Atlas of Ancient Egypt Oxford, PP. rr.

$$
\text { (“) جودة ، حسنين جودة ، جغر افيا مصر ، ( مصر - المجلس الأعلى للثقافة القاهرة) ، ؟99 ام ، ص99. }
$$

(“)Maspero, G. , The Dawn of Civlization, 19.1, P. ะ१९

$\left(^{\lambda r}\right)$ Adams , A , Nubia Corridor to Africa, London, I9vV , P.Av.

$\left({ }^{\lambda r}\right)$ Fakhry, A, The Inscription of the Amiethyst Quarries at Wadi El Hudi , Cairo, 190r, P. $) \leqslant$.

$\left.{ }^{\wedge \varepsilon}\right)$ Joyce L . Haynes, Nubia Ancient King Doms Of Africa, p . $\varepsilon v$.

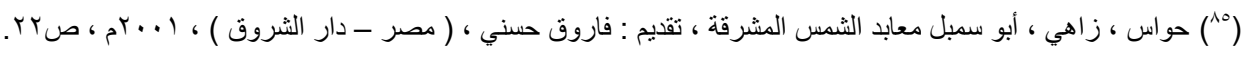

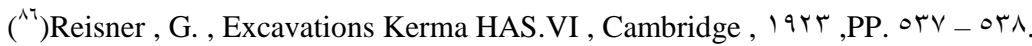

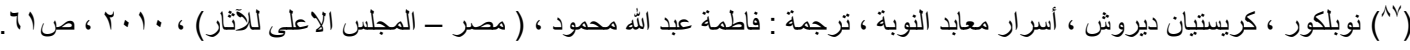

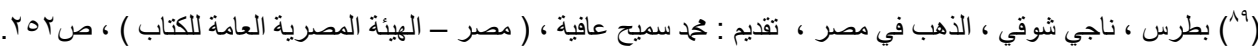

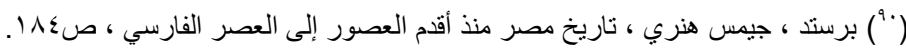

$$
\begin{aligned}
& \text { (") بطرس ، ناجي شوقي ، الذهب في مصر ، تقديم : محمد سميح عافية ، ( مصر - الهيئة المصرية العامة للكتاب ) ، ص ror ror - ror. }
\end{aligned}
$$

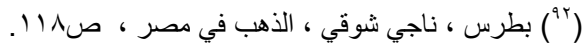

$\left(^{9 r}\right)$ G.Mokhtar, P. rvr.

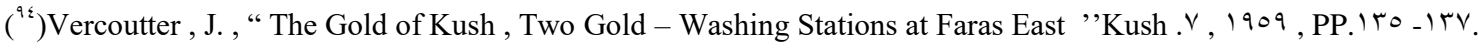

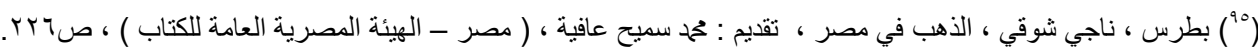

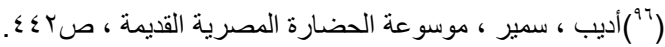

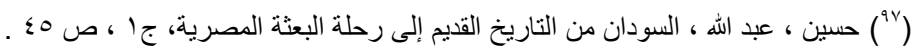

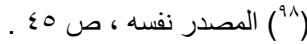

$\left({ }^{99}\right)$ G.Mokhtar, P.r $\ \wedge$ 
('..)G.Mokhtar,P.rฬ^; Roy, Jane ,The Politics of Trade Egypt and Lower Nubia in the $\varepsilon^{\text {th }}$ Millennium BC,Leiden.Boston ,, 1 ,P.r. \&.

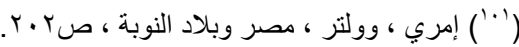

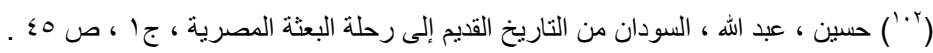

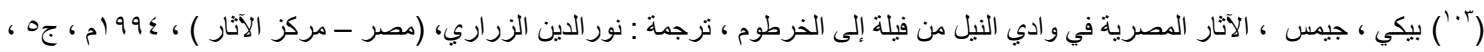

$$
\begin{aligned}
& \text {. } 11 \cdot 0 \cdot 119
\end{aligned}
$$

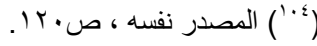

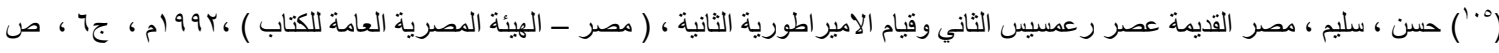

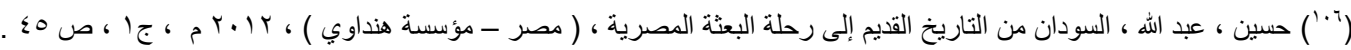

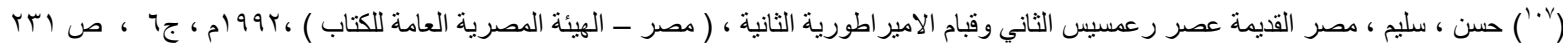

$$
\begin{aligned}
& \text { - صזrT. }
\end{aligned}
$$

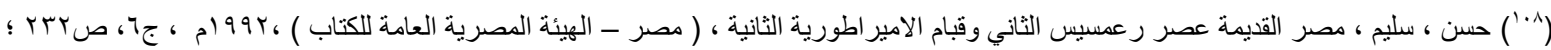

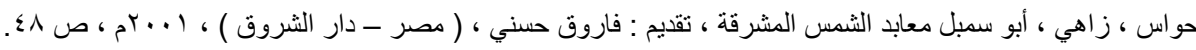

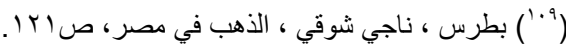

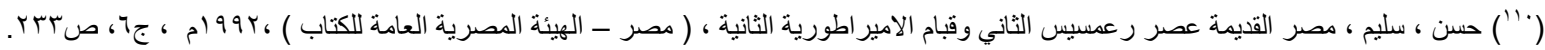

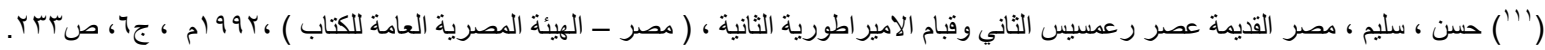

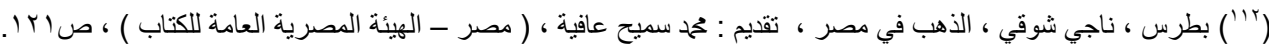

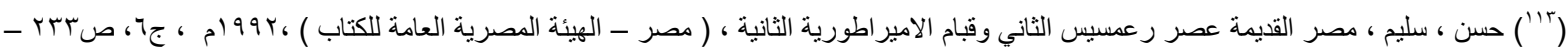

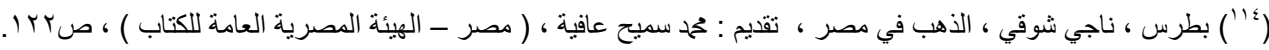

(110)Vercoutter, J., " The Gold of Kush, Two Gold - Washing Stations at Faras East 'Kush .V , 1909 , P. 1 .

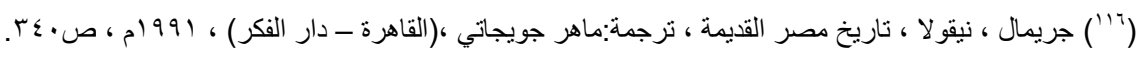

(' 'v)Vercoutter, J. , "The Gold of Kush, Two Gold - Washing Stations at Faras East "Kush . V , 1909, P. Ir.

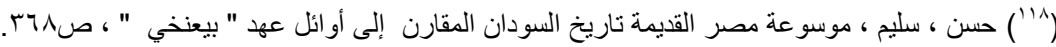

$$
\begin{aligned}
& \text { (1'19) بطرس ، ناجي شوقي ، الذهب في مصر ، تقيم : محم سميح عافية ، ( مصر - الهيئة المصرية العامة للكتاب ) ، صكץY. }
\end{aligned}
$$

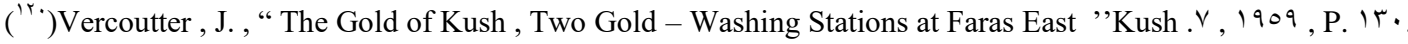

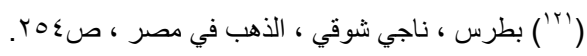

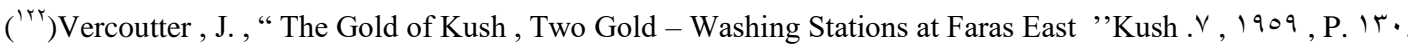

$\left({ }^{i r}\right)$ Vercoutter, J. , “New Egyptian Texts from the Sudan” Kush. IV , PP. . • - v).

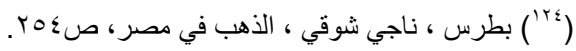

$\left({ }^{1 r o}\right)$ Adams , A , Nubia Corridor to Africa, London, $19 \vee \mathrm{V}$, P.^०.

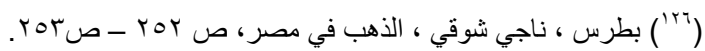

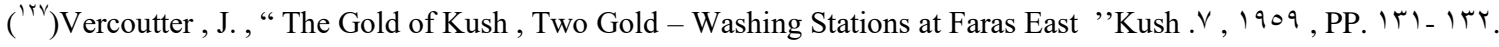

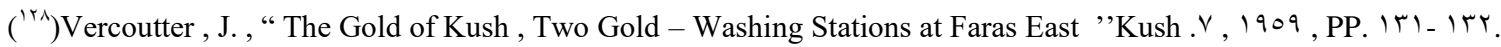

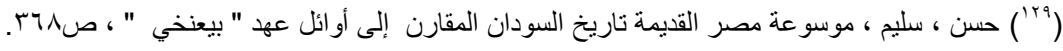

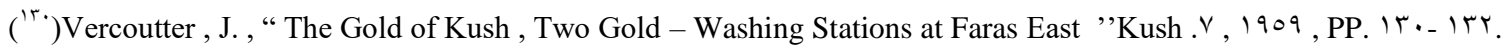

$\left({ }^{r \prime}\right)$ Vercoutter , J. , “ The Gold of Kush, Two Gold - Washing Stations at Faras East "'Kush . V , 1909, P. Irr. 


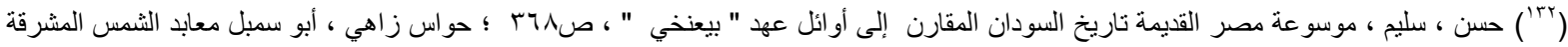

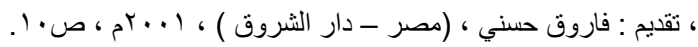

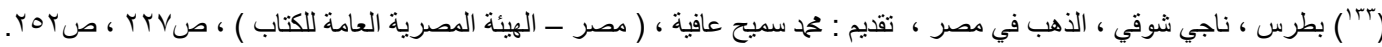

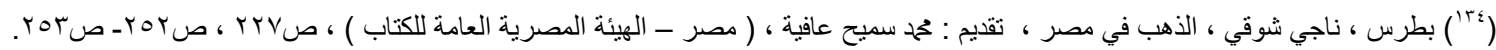

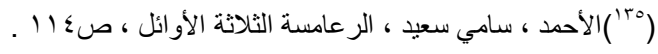

${ }^{(T)}$ A group of Researchers,Ancient Egyptian Jewelry Best Selection from the Egyptian Museum,P.17.

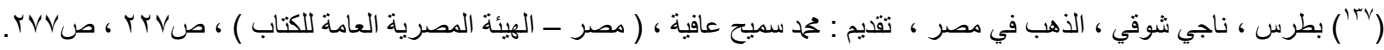

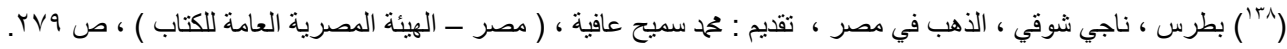

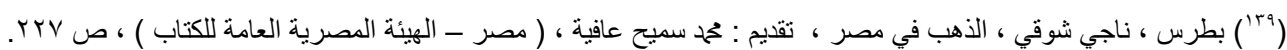

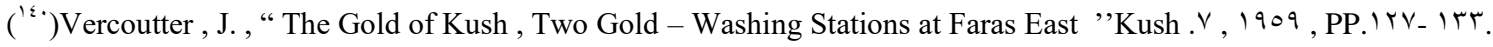

('s)Vercoutter, J., " The Gold of Kush, Two Gold - Washing Stations at Faras East ' Kush .V , 1909 , P. 1 .

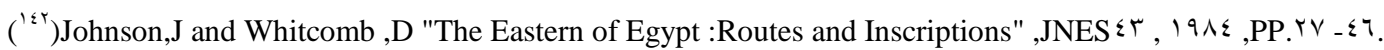

$\left({ }^{(\leqslant}\right)$Forbes ,R.J , Studies in Ancient Technology ,Vol ,Leiden, $197 \leqslant$, P. 17 r.

$\left(^{(\Sigma \varepsilon}\right)$ Harris ,J.R,Ancient Egyption Materials and Industries $\varepsilon^{\text {th }}$ Edition, London, 1974, P. $\{\wedge r$.

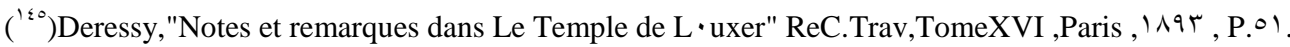

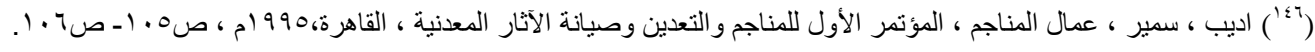

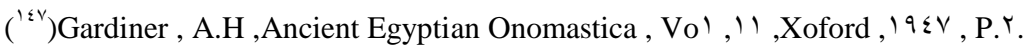

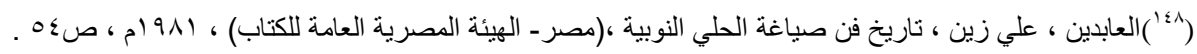

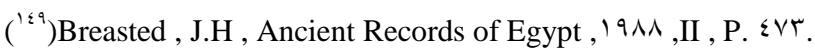

$\left.{ }^{10 .}\right)$ Baines ,J ,Atlas of Ancient Egypt Oxford , PP.rr.;Barton, Hume W.F, Topography and Geology of Eastern Desert of Egypt Centeral, London, $19 \cdot \mathrm{V}, \mathrm{PP} .1 \varepsilon_{-} 10$.

$\left({ }^{10}\right)$ Barton ,Hume,W.F ,Topography and Geology of Eastern Desert of Egypt Centeral, London, 19.V, PP.) $\varepsilon-10$.

$\left({ }^{10 r}\right)$ Breasted , J.H , Ancient Records of Egypt, $19 \wedge$,II ,PP. $\leqslant \leqslant V_{-} \leqslant$V 1.

$\left({ }^{\text {lor }}\right)$ Baines ,J ,Atlas of Ancient Egypt Oxford , PP. ${ }^{r}$.

$$
\text { ( }
$$

( ${ }^{100}$ ) Budge ,W,The Egyptian Sudan 11, London , 19.v,P.VV

$\left({ }^{107}\right)$ Murray ,The Road to chaphrens Quarries, $19 \vee 0$,Oxford ,P. Ir

$\left({ }^{\text {lov }}\right.$ Baines, Atlas of Ancient Egypt , $19 \vee 9$,Oxford ,P.r.

$\left.{ }^{\text {lod }}\right)$ Baines ,P.rr.

$\left({ }^{109}\right)$ Adams , A , Nubia Corridor to Africa, London, I9VV, P.Av.

('). Adams, A , P.^v.

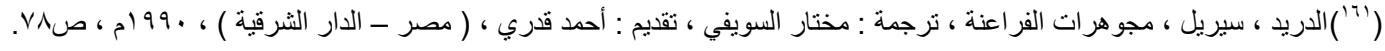

${ }^{(T)}$ A group of Researchers,Ancient EgyptianBreasted ,J.H Jewelry Best Selection from the Egyptian Museum,P. 17

$$
\begin{aligned}
& \text { (ז") ) حواس ،زاهي ، فنون صناعة الحلى في مصر القديمة مختارات مصورة من مقتتيات المتحف المصري ، ترجمة:سنثيا شيخ ، ( مصر - مطابع الأعلى }
\end{aligned}
$$

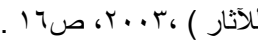

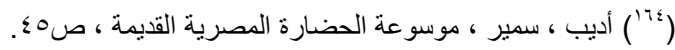

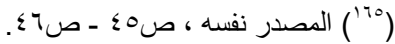


(المصدر نفسه، صT؟ (177)

$\left(^{17 V}\right.$ Reisner.A,Archaeologigal Survey of Nubia Report for $19 O^{\vee}-19 \cdot 1$ VolumeI, Harvard University, $191 \cdot$,P.VY.

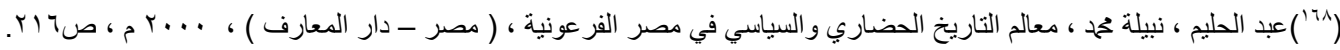

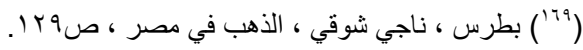

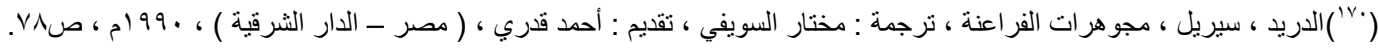

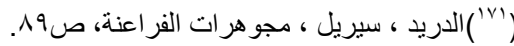

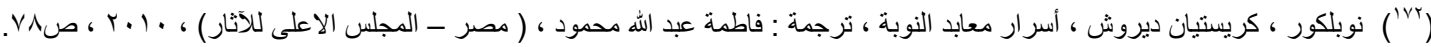

$\left({ }^{\mathrm{vr}}\right)$ Joyce L . Haynes, Nubia Ancient King Doms Of Africa, p . $\leqslant \vee$.

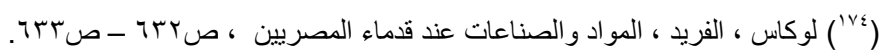

$\left({ }^{1 / 0}\right)$ Editor, G.Mokhtar,General History Of Africa .II Ancient Civilizations of Africa, Heinemann. Calfornia.Unesco, 1911, P. Y $Y$ r.

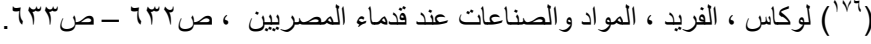

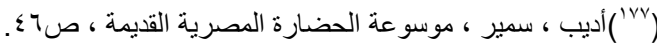

( $\left.{ }^{1 \vee \wedge}\right)$ Joyce L. Haynes, Nubia Ancient King Doms Of Africa, Museum Of Fine Arts, Boston Washington, 199r, p . $\leqslant \vee$.

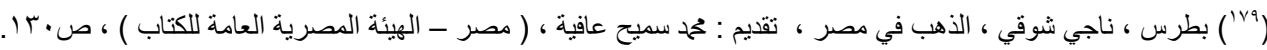

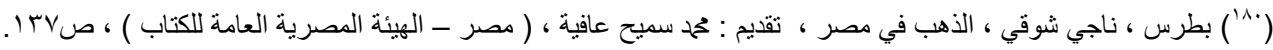

$$
\begin{aligned}
& \text { ('l') حو اس ،ز اهي ، فنون صناعة الحلى في مصر القديمة مختارات مصورة من مقتنيات المتحف المصري ، ترجمة:سنثيا شيخ ، ( مصر - مطابع الأعلى }
\end{aligned}
$$

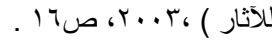

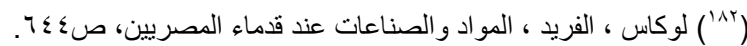

$\left({ }^{\wedge \wedge}\right)$ The Metropolitan Museum of Art, Ancient Egyptian Jewelry, APicture Book, New Yew York, $19 \varepsilon \cdot ., P .0$.

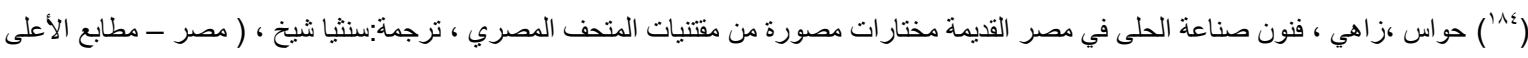

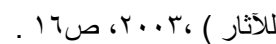

$$
\begin{aligned}
& \text { (1^) حو اس ،زاهي ، فنون صناعة الحلى في مصر القديمة مختارات مصورة من مقتتيات المتحف المصري ، ترجمة:سنثيا شيخ ، ( مصر - مطابع الأعلى }
\end{aligned}
$$

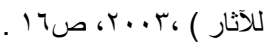

${ }^{(\Lambda \uparrow}$ ) Goyon,I.G ,Nouvelles Inscriptions Rupestres du Wadi Hammamat,Paris , 190V, P. $\leqslant 0$.

$\left({ }^{\wedge \wedge}\right)$ Fairman ,H.W,Preliminary Report on The Excavations at Amarah west Anglo-Egyptian Sudan, $19 \leqslant \vee$,p.^.

( ${ }^{\prime \wedge}$ ) Budge,W,The Egyptian Sudan 11, London, $19 \cdot v, P . \vee v$.

$\left({ }^{1 \wedge 9}\right)$ Breasted ,J.H,A History of Egypt ,London , 1909,P.^•

('9.)Vercoutter, J. , " The Gold of Kush, Two Gold - Washing Stations at Faras East "'Kush . V, 1909, PP. I YV_ Irr. (' $\left.{ }^{19}\right)$ Asfour, M . A . A, The Relation between Egypt and Nubia in Pharaonic Times, Ph . D .Unpublished, 1970 , PP. 1^. -

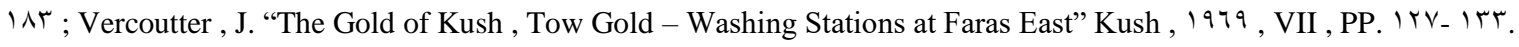
$\left({ }^{\prime 9 r}\right)$ Emery , W . B. , "Egypt Exploration Society Preliminary Report on the Excavations at Buhan 197r" Kush 11,197 , PP. $117-1 \% \cdot$.

$\left({ }^{\prime 9 r}\right)$ Fakhry, A . , The Inscription of the Amiethyst Quarries at Wadi El Hudi , Cairo , 190r, P. Y.

$\left({ }^{198}\right)$ Asfour, M . A . A, The Relation between Egypt and Nubia in Pharaonic Times, Ph . D .Unpublished, 1970, PP. 1 ^• IAr ; Vercoutter, J. "The Gold of Kush, Tow Gold - Washing Stations at Faras East" Kush, 1979 , VII , PP. IrV_ Irr.

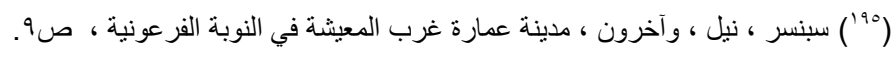$$
\text { (1971) موسى ، أحمد رشاد ، دراسات في تاريخ مصر الاقتصادي الدراسة الاولى حضارات ماقبل التاريخ وحضارة مصر الفرعونية ، ( مصر - المجلس }
$$

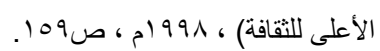




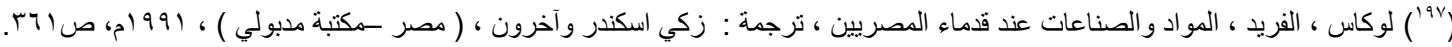

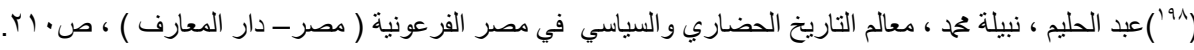
(999) بدوي ، اسكندر ، تاريخ العمارة المصرية عصر الأنتقال الأول و الدولة الوسطى وعصر الأنتقال الثاني، ترجمة : صلاح الدين رمضان محمد ، ( مصر -

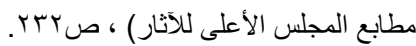
أولاً: المراجع العربع العربية:-

1- أديب ، سمير ، موسو عة الحضارة المصرية القديمة، ( القاهرة - مكتبة العربي) ، . . بكم .

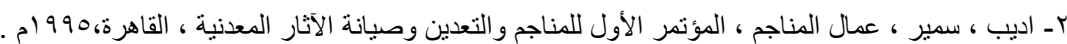

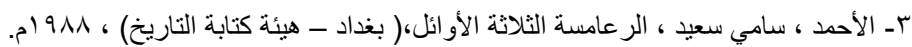

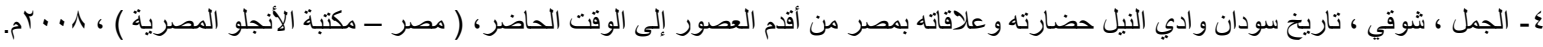

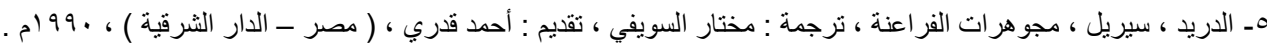

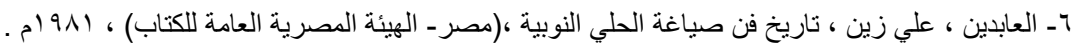

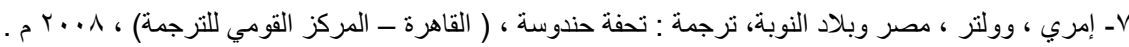

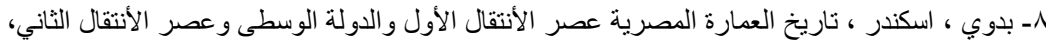

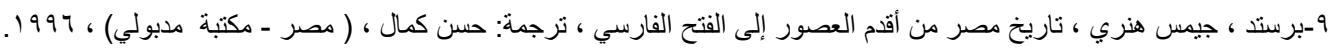
• 1- بطرس ، ناجي شوقي ، الذهب في مصر ، تقديم : تحمد سميح عافية ، ( مصر - الهيئة المصرية العامة للكتاب ).

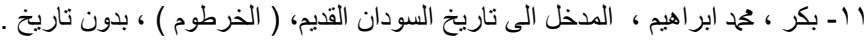

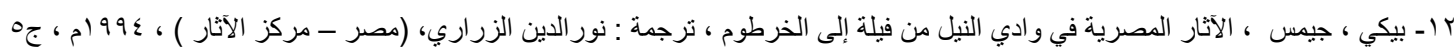

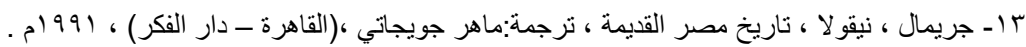

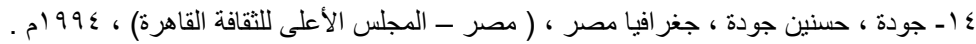

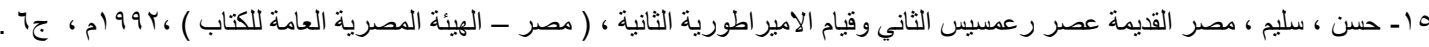

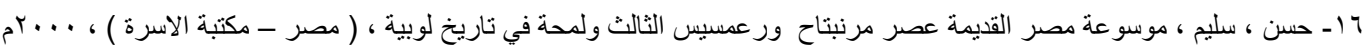

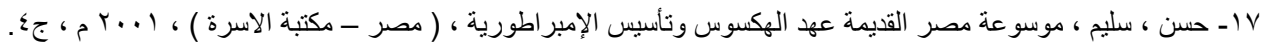

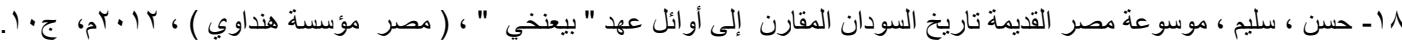

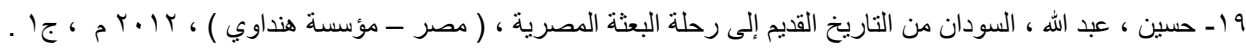

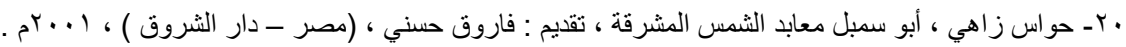

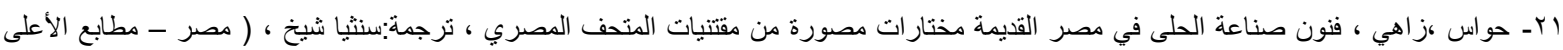

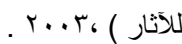

r بـ خليل ، عبد المجيد حسن ، النوبة الإنسان والتاريخ ، تقديم : فريدة النقاش ، ( مصر - مكتبة مدبولي ) .

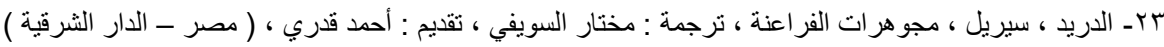

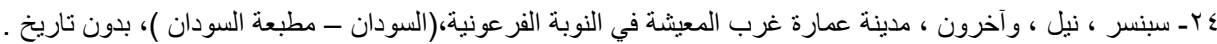

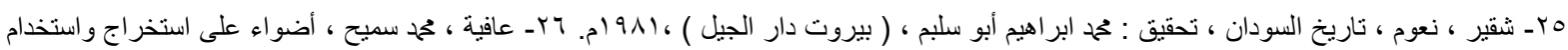

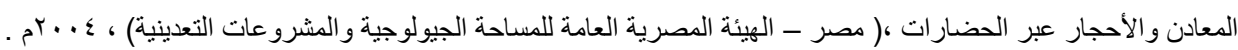

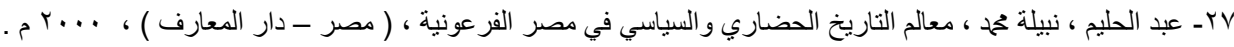

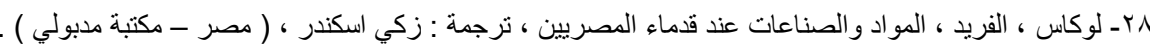

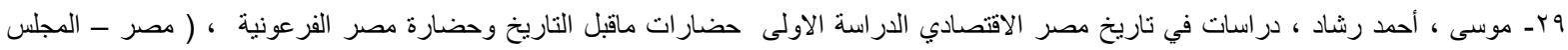

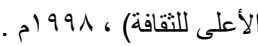

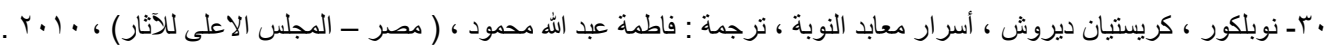

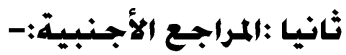

1. A group of Researchers,Ancient EgyptianBreasted ,J.H Jewelry Best Selection from the Egyptian Museum.

r. Adams, A, Nubia Corridor to Africa, London, 19v .

r. Baines, Atlas of Ancient Egypt „ $19 \vee 9$,Oxford.

๕. Ball .J , The Geog and Geol of South Eastern Egypt. 
๑. Barton ,Hume,W.F ,Topography and Geology of Eastern Desert of Egypt Centeral, London, 19.v.

ฯ. Breasted .J.H, Ancient Nubia Press Kit, The Museum of the Oriental lnstitute at the University of Chicago , February, r..

$\checkmark$. Breasted , J.H , Ancient Records of Egypt , $194 \Lambda$.

^. Budge,E.A.W,The Egyptian Sudan, $r$ Vo's, London, $19 \cdot r$.

१. Coghlan, H.H , Some Fresh Aspects of the Prehistoric Metallurgy of Copper, The Antiquaries Journal, XXII, $19 \leqslant$ r.

1. Darnell .John, The Stela of the Viceroy Usersatet (Boston MFA ro 7 rr r), his Shrine at Qasr Ibrim, and the Festival of Nubian Tribute under Amenhotep II.

1). Deressy,"Notes et remarques dans Le Temple de L· uxer" ReC.Trav,TomeXVI ,Paris, , ^९ץ.

1 r. Editor, G.Mokhtar,General History Of Africa .II Ancient Civilizations of Africa, Heinemann. Calfornia.Unesco, 19^1.

Ir. Emery, W.B,Egypt Exploration Society Preliminay Report on the excavations at Buhan, 1947 , Kush ,XI, 9 ฯ.

1 ..Fakhry, A, The Inscription of the Amiethyst Quarries at Wadi El Hudi, Cairo, $190 \mathrm{r}$.

10. Forbes, R.J, Studies in Ancient Technology, Vol ,Leiden, 197 .

17. Fuchs ,R.,"silver" LAV.

1V. Gardiner, A.H ,Ancient Egyptian Onomastica, Vo 1,11 ,Xoford , $19 \leqslant \mathrm{~V}$.

१^. Giveon ,R, The Impact of Egypt on cannaan ,Iconographical and Related Studies, London, $19 \vee \wedge$.

19. Harkless, Necia Desiree, Nubian Pharaohs And Meroitic Kings The

Kingdom Of Kush, Printed in the States of America, Bloomington Indiana , $r \cdots r$.

$r \cdot$. Harris ,J.R,Ancient Egyption Materials and Industries $\varepsilon^{\text {th }}$ Edition, London, 197 .

$r$. Haycock Bryan .G, The foreign relations of the Napatan - Meroitic Kingdom in the Sudan From the $\wedge^{\text {th }}$ Century B.Cto the $\varepsilon^{\text {th }}$ Century A.D, theses Durham University, 1970.

rr. Hill , M "A Bronze Statuette of Thutmos III, The Metropolitan Museum of Art Journal rv, 199v.

rr.Hornung,E,Der Agytische Mythes der Himmelskuh,Leipzig, $19 \wedge r$,P. $r$ V.

$r \varepsilon$. Johnson,J and Whitcomb ,D "The Eastern of Egypt :Routes and Inscriptions" ,JNES $\varepsilon$, , 19^£.

ro. Joyce L. Haynes, Nubia Ancient King Doms Of Africa, Museum Of Fine Arts, Boston Washington, 199 r.

r..Maspero, G. , The Dawn of Civlization , 19.1.

Yv. Reisner.A,Archaeologigal Survey of Nubia Report for $190^{V}-19 \cdot 1$ VolumeI, Harvard University, 191 .

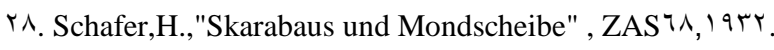

५ . Steindorff ,G.,Aniba II,Text -Tafeln, Gluckstadt, 19 १ .

$r \cdot$ The Metropolitan Museum of Art, Ancient Egyptian Jewelry, APicture Book, New Yew York, $19 \varepsilon \cdot$

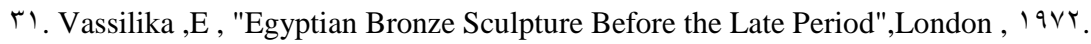

rr. Vercoutter, J. , “ The Gold of Kush, Two Gold - Washing Stations at Faras East 'Kush . $\vee$, 1909. r.. Wilkinson, J .G, The Ancient Egyptians, London, $1 \wedge 9$. 